\title{
High manure load reduces bacterial diversity and network complexity in a paddy soil under crop rotations
}

\author{
Haiyang Liu ${ }^{1,2}$, Xing Huang ${ }^{1}$, Wenfeng Tan ${ }^{2}$, Hongjie $\mathrm{Di}^{1}$, Jianming $\mathrm{Xu}^{1}$, Yong $\mathrm{Li}^{1,{ }^{*}}$ \\ 1 Institute of Soil and Water Resources and Environmental Science, College of Environmental and Resource Sciences, Zhejiang Provincial Key \\ Laboratory of Agricultural Resources and Environment, Zhejiang University, Hangzhou 310058, China \\ 2 Key Laboratory of Horticultural Plant Biology, The Ministry of Education, College of Resources and Environment, Huazhong Agricultural \\ University, Wuhan 430070, China
}

\section{ARTICLE IN FO}

\section{Article history:}

Received January 13, 2020

Revised March 11, 2020

Accepted March 20, 2020

Keywords:

Manure application

Rotation

Diversity

Bacterial community

Sequencing

\begin{abstract}
A B S T R A C T
Long-term application of chemical fertilizers causes soil degradation and nitrogen $(N)$ loss, but these effects could be alleviated by organic fertilizers. In addition, crop rotation is a feasible practice to increase soil fertility, soil quality and crop yields comparing with monocultural cropping patterns. However, questions remain concerning how the soil microbiome responds to different manure application rates under crop rotations. Here, we collected soil samples from a rice-rape system to investigate the response of the soil microbiome to nine years of pig manure application at different rates (CK: $0 \mathrm{~kg} \mathrm{ha}^{-1}, \mathrm{M1}: 1930 \mathrm{~kg} \mathrm{ha}^{-1}, \mathrm{M2}: 3860 \mathrm{~kg} \mathrm{ha}^{-1}$ and M3: $5790 \mathrm{~kg} \mathrm{ha}^{-1}$ ). Our results revealed that the bacterial $\alpha$-diversity (Chao1 and Shannon index) in the rape season increased first and then decreased with increasing manure application rates, and a high manure load tended to decrease the bacterial $\alpha$-diversity in the rice season. Long-term manure application enriched some copiotrophic bacteria, such as Proteobacteria and Actinobacteria, while it decreased the relative abundance of Nitrospirae. Redundancy analysis (RDA) and the Mantel test indicated that soil pH, TC, TN, AP, C/P and $N / P$ ratios were the main factors influencing bacterial communities. Moreover, network analysis showed that a low manure application rate shaped a complexly connected and stable bacterial community, while higher manure application rate decreased the stability of the bacterial network. These findings improve our understanding of bacterial responses to longterm manure application under crop rotations and their relationships with soil factors, especially in the context of increasing fertilizer inputs.
\end{abstract}

(C) Higher Education Press 2020

\section{Introduction}

Fertilization is an essential agricultural practice to increase crop yield and quality by improving soil nutrients, which can change soil physical and chemical properties and microbial

\footnotetext{
* Corresponding author

E-mail address: liyongcn@zju.edu.cn (Y. Li)
}

communities (Marschner et al., 2003; Li et al., 2017). Chemical fertilization is the most common practice in agricultural production. However, large amounts of chemical fertilizer have been applied to soil over the past few decades to feed a growing world. Excessive chemical fertilizer application can cause a series of environmental problems, such as soil degradation, nitrogen $(\mathrm{N})$ leaching, greenhouse effects (Sun et al., 2015; Wang et al., 2018), and consequently decreases in crop yields (Horrigan et al., 2002). Therefore, 
new and environmentally friendly strategies are urgently needed to mitigate the adverse effects of the long-term application of chemical fertilizers.

It is well known that organic fertilizers such as manures, composts and crop residues can increase soil quality and plant growth by supplying nutrients (Reeves, 1997; Cavagnaro, 2014). Organic amendments can maintain soil productivity (Steiner et al., 2007), increase soil carbon (C) stocks (Mando et al., 2005; Hemmat et al., 2010), improve soil structure and water retention (Yu et al., 2012) and suppress various soil-borne diseases (Bailey and Lazarovits, 2003; Litterick et al., 2004). For example, substituting livestock manure for synthetic $\mathrm{N}$ fertilizer significantly increases crop yield and soil organic carbon (SOC) sequestration and decreases $\mathrm{N}$ loss via a global meta-analysis (Xia et al., 2017). In addition, numerous studies have indicated that crop rotation is an alternative strategy to increase soil fertility, maintain soil quality and increase crop yield when compared with monocultural cropping patterns (Xuan et al., 2012; Tiemann et al., 2015; Venter et al., 2016). Crop rotation is also used for breaking weed and disease cycles, and for maintaining soil structure (Smith et al., 2008).

Soil microorganisms play a critical role in maintaining soil quality, productivity and ecological balance through biogeochemical processes such as nutrient cycling and residue decomposition (Li et al., 2014; Liu et al., 2019). Numerous studies have addressed how different fertilization regimes alter the diversity and structure of bacterial community. For example, 34 years of fertilizer application causes a reduction in both bacterial biodiversity and abundance (Zhou et al., 2015). In contrast, the application of NPK fertilizer combined with manure is found to maintain bacterial diversity (Sun et al., 2015). The relative abundance of some copiotrophic bacteria is usually induced by organic fertilizer (Hartmann et al., 2015; Wang et al., 2017), while oligotrophic bacteria such as Bacteroidetes and Acidobacteria are enriched by chemical fertilizer (Wang et al., 2017). It is widely acknowledged that fertilizer type is an important factor affecting soil microbial communities (Zhong et al., 2010; Zhang et al., 2012). However, only a few studies have focused on the changes in soil bacterial communities driven by different rates of manure application. A previous study with different manure doses $(5 \%, 10 \%, 15 \%, 20 \%, 25 \%)$ demonstrates that $10 \%$ manure application is optimal for apple orchards and the soil become more biologically active under those conditions (Sun et al., 2014). The soil microbial community and diversity vary among crop species (Reinholdhurek et al., 2015). Crop rotations lead to a greater abundance and diversity of plant litter, which in turn can support a greater diversity of microbial decomposers in soil (Kennedy, 1999). Crop rotation has a positive effect on the abundance of beneficial microorganisms (Warembourg et al., 2003; Larkin and Honeycutt, 2006) and suppresses disease (Peters et al., 2003; Mendes et al., 2011). For example, rice-mungbean-rice rotation harbours more bacteria clustering with the beneficial Herbaspirillum sp. and $B$. vietnamensis belonging to $\beta$-Proteobacteria (Xuan et al.,
2012). Hence, understanding the shifts in soil bacterial community structure and composition following different manure amendment rates, especially under crop rotation systems, may have significant implications for the development of sound management strategies for agroecosystems.

Fertilization affects microbial communities through influence on soil nutrient contents and chemistry (Peacock et al., 2001; Zhong et al., 2010), and crops impact the soil microbiota through root exudates and plant residues by altering soil $C$ inputs and nutrient availability ( $\mathrm{Ai}$ et al., 2015).The soil bacterial community is a potential indicator to assess the environmental impacts of agricultural practices on soil quality (Sharma et al., 2011) and is sensitive to change in the soil environment from human activities and natural disturbance (Yin et al., 2010). Previous studies have emphasized the importance of soil variables to bacterial communities with different fertilizer regimes. For instance, soil pH and available $\mathrm{N}$ significantly influence bacterial communities (Kumar et al., 2018). Similarly, another long-term fertilization study demonstrates that soil bacterial diversity and communities are shaped by changes in soil pH rather than the direct effect of nutrient addition (Zhang et al., 2017). Furthermore, SOC (Li et al., 2017; Ji et al., 2018) and available phosphorus (AP) contents (Yang et al., 2017; Zhou et al., 2017) are also found to be important factors influencing soil bacterial communities. Therefore, it is critical to further investigate the relationship between soil factors influenced by agricultural production practices such as fertilization and crop rotation and bacterial communities.

In the present study, soils collected from a paddy soil with a rice-rape cropping system in South China were subjected to 9 years of manure application with various rates. The Illumina MiSeq sequencing platform was used to characterize the responses of the bacterial communities to the different longterm manure application rates during rice and rape seasons. We hypothesized that the different long-term manure fertilization rates and crop rotation could result in shifts in the bacterial diversity and community, and such shifts might be partly caused by changes in soil physicochemical properties following long-term manure application and crop rotation.

\section{Materials and methods}

\subsection{Site description and design}

The field experimental site was located in Jiaxing city $\left(30^{\circ} 50^{\prime}\right.$ $\left.\mathrm{N}, 120^{\circ} 40^{\prime} \mathrm{E}\right)$ in the Taihu Lake region, Zhejiang Province, China. This area has a subtropical monsoon climate with mean annual rainfall and temperatures of $1200 \mathrm{~mm}$ and $15.7^{\circ} \mathrm{C}$, respectively. The experiment began in 2005 and has continued since then. A rice-rape (Brassica napus) rotation was the common cropping system, where the rice season lasted from June to November and the rape season lasted from November to May. The soil was classified as a gleyed paddy soil derived from riverine-lacustrine sediments. At the beginning of the experiment, the soil of the plough layer had a 
$\mathrm{pH}$ (soil to water ratio was 1:2.5) of 6.9, organic $\mathrm{C}$ of 18.2 $\mathrm{g} \mathrm{kg}^{-1}$, total $\mathrm{N}$ of $2.65 \mathrm{~g} \mathrm{~kg}^{-1}$, total $\mathrm{P}$ of $1.51 \mathrm{~g} \mathrm{~kg}^{-1}$ and soil cation exchange capacity (CEC) of $8.12 \mathrm{cmol} \mathrm{kg}^{-1}$ (Liang et al., 2013).

Four treatments were arranged in a randomized complete block design with three replications in 12 plots $(4 \mathrm{~m} \times 5 \mathrm{~m})$ consisting of soil without fertilizer (control, $\mathrm{CK}$ ) and three $\mathrm{N}$ application rates $\left(90,180\right.$, and $\left.270 \mathrm{~kg} \mathrm{~N} \mathrm{ha}^{-1}\right)$ applied as pig manure (M1, M2 and $\mathrm{M} 3$ ). The total $\mathrm{N}$ and $\mathrm{P}_{2} \mathrm{O}_{5}$ in manure were $37.3 \mathrm{~g} \mathrm{~kg}^{-1}$ and $29.0 \mathrm{~g} \mathrm{~kg}^{-1}$, respectively. Eighty percent of pig manure was applied as the basal $\mathrm{N}$ fertilizer, and the remaining $20 \%$ of the $\mathrm{N}$ was applied as urea in two equal topdressing doses. Thus, the total amounts of manure in the CK, M1, M2 and M3 treatments were 0, 1930, 3860 and 5790 $\mathrm{kg} \mathrm{ha}^{-1}$, respectively. Guard plots planted with rice were established around the entire experimental area to reduce edge effects. The rice hill spacing was 15 by $15 \mathrm{~cm}$, and the rape hill spacing was 40 by $50 \mathrm{~cm}$. The local dominant cultivars of rice and rape were selected for the experiment. Field practices, such as field preparation, tillage, puddling, irrigation, and weed control, were performed according to the local farmers. Irrigation water was maintained 5 to $8 \mathrm{~cm}$ above the ground before the maturity period of rice and drained during the rape season with $60 \%$ water content in the topsoil.

\subsection{Sampling and soil properties analysis}

Soil samples of rice season and rape season were collected in November, 2013 and May, 2014, respectively. For each plot, soil samples were collected from 5 random locations a depth of $0-15 \mathrm{~cm}$ and were mixed as one soil sample for each replicate, with aboveground plant materials, roots, and stones removed. All the soil samples were immediately transported on ice to the laboratory. A portion of the soils was used for physicochemical property analysis, and a sub-sample was used for DNA extraction and Miseq sequencing.

Soil $\mathrm{pH}$ was measured using a Satorius basic $\mathrm{pH}$ meter (Sartorius Scientific Instruments Co. Ltd., Beijing, China) with a 1:2.5 soil to water ratio. The total $C(T C)$ and $N(T N)$ were determined using an elemental analyzer (Elementar Analysensysteme $\mathrm{GmbH}$., Germany). Soil total $P$ was determined by the molybdenum antimony anti-colorimetric method. Available $P$ in soil was extracted by sodium bicarbonate and determined using the molybdenum blue method (Olsen, 1954). Available potassium in soil was extracted by ammonium acetate and determined with flame photometry (nova 300, Analytic Jena, Germany) (Carson, 1980). Mineral N in soil was extracted with $1 \mathrm{M} \mathrm{KCl}$ in a 1:10 soil to solution ratio for $1 \mathrm{~h}$, and the extracts were measured by a flow injection analyzer (SAN ++, Skalar, Netherlands).

\subsection{DNA extraction, MiSeq sequencing and data analysis}

Soil total DNA was extracted using $0.5 \mathrm{~g}$ fresh soil with a FastDNA spin kit for soil (MP Biomedicals, OH, USA) according to the manufacturer's protocol. The concentration and quality of DNA were determined by a Nanodrop spectro- photometer (NanoDrop Technologies, Wilmington, DE, USA) and gel electrophoresis, respectively, and the DNA was stored at $-20^{\circ} \mathrm{C}$ until ready for MiSeq sequencing.

Bacterial 16S rRNA gene amplification of the $\mathrm{V} 4-\mathrm{V} 5$ region was conducted using the primer pair 515F (5'- GTG CCA GCM GCC GCG G-3') and 907R (5' - CCG TCA ATT CMT TTR AGT TT- $3^{\prime}$ ) (Stubner 2002). The $20 \mu \mathrm{L}$ PCR contained $4 \mu \mathrm{L}$ of $5 \times$ FastPfu Buffer, $0.4 \mu \mathrm{L}(2.5 \mathrm{U} / \mu \mathrm{L})$ of TransStart Fastpfu polymerase (TransGen, Beijing, China), $0.8 \mu \mathrm{L}(5 \mu \mathrm{M})$ of each forward/reverse primer, $2 \mu \mathrm{L}(2.5 \mathrm{mM})$ of dNTP, $10 \mathrm{ng}$ of DNA template and Milli-Q water to the final volume. The thermal conditions were as follows: $3 \mathrm{~min}$ at $95^{\circ} \mathrm{C} ; 27$ cycles of $30 \mathrm{~s}$ at $95^{\circ} \mathrm{C}, 30 \mathrm{~s}$ at $55^{\circ} \mathrm{C}$, and $45 \mathrm{~min}$ at $72^{\circ} \mathrm{C}$; and $10 \mathrm{~min}$ at $72^{\circ} \mathrm{C}$. PCR products were purified using a QIAquick PCR purification kit (Qiagen, Shenzhen, China) and quantified using a Nanodrop spectrophotometer (Thermo Scientific, Waltham, MA, USA). The size and quality of PCR products were examined on a $2 \%$ agarose gel. The purified and quantified amplicons were pooled in equimolar concentrations, and the paired-end $250 \mathrm{bp}$ reads were run on an Illumina MiSeq apparatus using MiSeq Reagent Kit V2 according to the manufacturer's instructions. The sequence data were submitted to the National Center for Biotechnology Information (NCBI) Sequence Read Archive with accession number SRP229408.

The raw sequencing data were processed using Quantitative Insights into Microbial Ecology (QIIME) software (Caporaso et al., 2010). Sequences with mismatched primers, ambiguous characters, quality scores below 20 and read lengths shorter than $200 \mathrm{bp}$ were excluded from the analysis. Chimeras were deleted and removed using UCHIME (Edgar et al., 2011). In total, 887882 high-quality sequences were obtained with an average length of $396 \mathrm{bp}$ from all 24 samples. These sequences were clustered into operational taxonomic units (OTUs) at $97 \%$ identity using UCLUST (Edgar, 2010), and 5520 OTUs were obtained. OTU table was rarefied according to the sample with the lowest number of reads (17733 reads). OTU taxonomic classification was conducted by the Ribosomal Database Project (RDP) classifier (Sul et al., 2011) using the Silva 16S rRNA database (Release 123) with a confidence threshold of $70 \%$.

\subsection{Community bioinformatics and statistics}

Community richness and diversity were estimated using the Chao 1 and Shannon index, respectively, and differences in $\alpha$ diversity among treatments were assessed by box plots and analysis of variance (ANOVA). The relationships between $\alpha$ diversity and soil physicochemical properties were analyzed by the Pearson correlation coefficient. Linear discriminant analysis effect size (LEfSe) was performed at http://huttenhower.sph.harvard.edu/lefse/ (Segata et al., 2011) to investigate the potential biomarkers within soil microbiomes specifically enriched in each treatment during the rice and rape seasons based on $P<0.05$ and a LDA score $>3.0$. Principal coordinate analysis ( $\mathrm{PCoA}$ ) was used to assess the differences in microbial communities based on Bray-Curtis 
similarity matrices in R (v3.4.0). Redundancy analysis (RDA) was used to identify the relationship between soil microbial communities and edaphic variables with the vegan package in R. Variance partitioning analysis (VPA) was conducted to quantify the relative contributions of soil chemical properties, manure rates and the cropping system using the "vegan" package in the $R$ environment. Permutational multivariate analysis of variance (PERMANOVA) based on Bray-Curtis distance matrices was performed in the vegan package. The relationships between various edaphic variables were analyzed by Spearman correlations in R. The associations of soil bacterial communities and edaphic variables were estimated by the Mantel test (Diniz-Filho et al., 2013). Random forest analysis was used to evaluate the associations between soil bacteria (top 15 phyla) and edaphic variables using the randomForest in $\mathrm{R}$ package (Bahram et al., 2018).

Network analysis was conducted on bacterial OTUs and soil properties by the Cytoscape (v3.6.1) plugin CoNet (Faust and Raes, 2012). The OTUs with a summed relative abundance less than $0.01 \%$ were removed from the network analysis (Ma et al., 2016). The analysis was performed with Bray-Curtis distance, Kullback-Leibler dissimilarity, Person and Spearman correlation (Faust and Raes, 2012) with a threshold of 0.7 . For each edge and measure, permutation and bootstrap distributions were generated with 1000 iterations. The $P$ values were merged using Brown's method (Brown, 1975) and then adjusted by Benjamini-Hochberg multiple-test corrections (Benjamini and Hochberg, 1995). Network topological characteristics were calculated using the NetworkAnalyser tool in Cytoscape (Li et al., 2017). The networks were visualized by the Fruchterman-Reingold layout in the Gephi (v 0.9.1) program (Bastian et al., 2009).

\section{Results}

\subsection{Soil physicochemical properties}

The long-term application of different manure rates had impacts on the soil physiochemical properties during rice and rape seasons (Table 1). Manure application significantly $(P<0.05)$ increased soil $\mathrm{pH}$ compared with those in the $\mathrm{CK}$ treatments in both seasons. However, no significant differences were found among manure treatments except for that between M1 and M3 treatments in the rice season. Significant $(P<0.05)$ differences in soil TC were observed between all treatments in the rice and rape seasons except for that between M2 and M3 treatments in the rape season. The soil TN content increased progressively with increasing manure rate, and the M3 treatments had the highest TN of $5.87 \mathrm{~g} \mathrm{~kg}^{-1}$ and $4.20 \mathrm{~g} \mathrm{~kg}^{-1}$ in the rice and rape seasons, respectively. The soil AP content was significantly $(P<0.05)$ enhanced by the different amounts of manure in all treatments except for the $\mathrm{M} 1$ and M2 treatments in the rice season. In addition, the AP contents in the rape season were significantly higher $(P<0.05)$ than those in the rice season in the corresponding manure treatments. For soil available potassium (AK), M1 and M2 significantly $(P<0.05)$ decreased the AK content by $50.3 \%$ and $39.3 \%$ in the rice season, respectively, but increased the AK content in the rape season in comparison to the CK. However, there were no significant differences in the soil $\mathrm{NH}_{4}{ }^{+}-\mathrm{N}$ contents between the treatments. The soil $\mathrm{NO}_{3}{ }^{-} \mathrm{N}$ content first increased and then decreased, with the highest concentrations of $22.69 \mathrm{mg} \mathrm{kg}^{-1}$ and $112.47 \mathrm{mg} \mathrm{kg}^{-1}$ in the M2 treatments during the rice and rape seasons, respectively. Similarly, the $\mathrm{NO}_{3}{ }^{-} \mathrm{N}$ contents in the rape season were significantly $(P<0.05)$ higher than those in the rice season in the corresponding treatments. C/P and N/P ratios increased in the rice season and decreased in the rape season with increasing manure rates.

\section{2 a-diversity and bacterial community composition}

The Chao 1 and Shannon index were used to measure the microbial alpha-diversity of each soil sample (Fig. 1). In the rape season, the Chao 1 and Shannon index increased first and then decreased with increasing manure rates and reached the highest values of 4285 and 6.84 in the M2 treatment, respectively (Fig. 1). In the rice season, the Shannon index decreased with increasing manure amount (Fig. 1B), and long-term manure application had no significant

Table 1 Soil properties in different manure treatments.

\begin{tabular}{|c|c|c|c|c|c|c|c|c|c|c|c|c|}
\hline & Treatment & $\mathrm{pH}$ & $\begin{array}{l}\text { TC } \\
\left(\mathrm{g} \mathrm{kg}^{-1}\right)\end{array}$ & $\begin{array}{l}\text { TN } \\
\left(\mathrm{g} \mathrm{kg}^{-1}\right)\end{array}$ & $\begin{array}{l}\text { TP } \\
\left(\mathrm{g} \mathrm{kg}^{-1}\right)\end{array}$ & $\begin{array}{l}\text { AP } \\
\left(\mathrm{mg} \mathrm{kg}^{-1}\right)\end{array}$ & $\begin{array}{l}\text { AK } \\
\left(\mathrm{mg} \mathrm{kg}^{-1}\right)\end{array}$ & $\begin{array}{l}\mathrm{NH}_{4}^{+}-\mathrm{N} \\
\left(\mathrm{mg} \mathrm{kg}^{-1}\right)\end{array}$ & $\begin{array}{l}\mathrm{NO}_{3}^{-}-\mathrm{N} \\
\left(\mathrm{mg} \mathrm{kg}^{-1}\right)\end{array}$ & $\mathrm{C} / \mathrm{N}$ & $\mathrm{C} / \mathrm{P}$ & $\mathrm{N} / \mathrm{P}$ \\
\hline \multirow[t]{4}{*}{ Rice } & CK & $6.98 c$ & $29.8 d$ & $2.90 \mathrm{c}$ & $1.41 \mathrm{~d}$ & $7.7 \mathrm{c}$ & $163 a$ & $13.58 a$ & $1.00 c$ & $10.3 a$ & $21.0 \mathrm{c}$ & $2.0 \mathrm{~b}$ \\
\hline & M1 & $7.31 b$ & $38.6 c$ & $3.73 b c$ & $1.59 c$ & $45.6 \mathrm{~b}$ & $81 b$ & $17.87 a$ & $3.32 c$ & $10.3 a$ & $24.3 b$ & $2.3 b$ \\
\hline & M2 & 7.51ab & $44.1 \mathrm{~b}$ & $4.87 a b$ & $1.68 b$ & $53.9 b$ & $99 b$ & $20.60 a$ & $22.69 a$ & $9.2 a$ & $26.2 b$ & $2.9 a b$ \\
\hline & M3 & $7.68 a$ & $51.2 a$ & $5.87 a$ & $1.75 a$ & $98.9 a$ & $166 a$ & $18.02 a$ & $9.85 b$ & $9.0 a$ & $29.2 a$ & $3.3 a$ \\
\hline \multirow[t]{4}{*}{ Rape } & $\mathrm{CK}$ & $6.91 \mathrm{~b}$ & $24.9 c$ & $2.30 \mathrm{c}$ & $1.21 \mathrm{~d}$ & $12.6 \mathrm{~d}$ & $81 \mathrm{c}$ & $12.65 a$ & $66.68 b$ & $10.8 a$ & $20.6 a$ & $1.9 a$ \\
\hline & M1 & $7.51 \mathrm{a}$ & $34.4 b$ & $3.27 b$ & $2.33 c$ & $78.9 c$ & $91 \mathrm{bc}$ & $12.76 a$ & $107.81 \mathrm{a}$ & $10.5 a b$ & $14.8 b$ & $1.4 b$ \\
\hline & M2 & $7.67 a$ & $40.8 a$ & $3.93 a$ & $2.87 \mathrm{~b}$ & $152.6 \mathrm{~b}$ & $106 a$ & $16.04 a$ & $112.47 a$ & 10.3ab & $14.2 b$ & $1.4 b$ \\
\hline & M3 & $7.55 a$ & $43.0 a$ & $4.20 \mathrm{a}$ & $3.17 \mathrm{a}$ & $172.9 a$ & $100 a b$ & $15.87 a$ & $56.23 b$ & $10.3 b$ & $13.6 \mathrm{~b}$ & $1.3 b$ \\
\hline
\end{tabular}

CK, M1, M2 and M3 represent manure application rates of 0, 1930, 3860 and $5790 \mathrm{~kg} \mathrm{ha}^{-1}$, respectively. TC, TN, TP, AP and AK represent soil total carbon, total nitrogen, total phosphorus, available phosphorus and available potassium contents, respectively. Values are means for triplicate replicates. Different letters indicate significant differences $(P<0.05)$ based on the analysis of variance. 

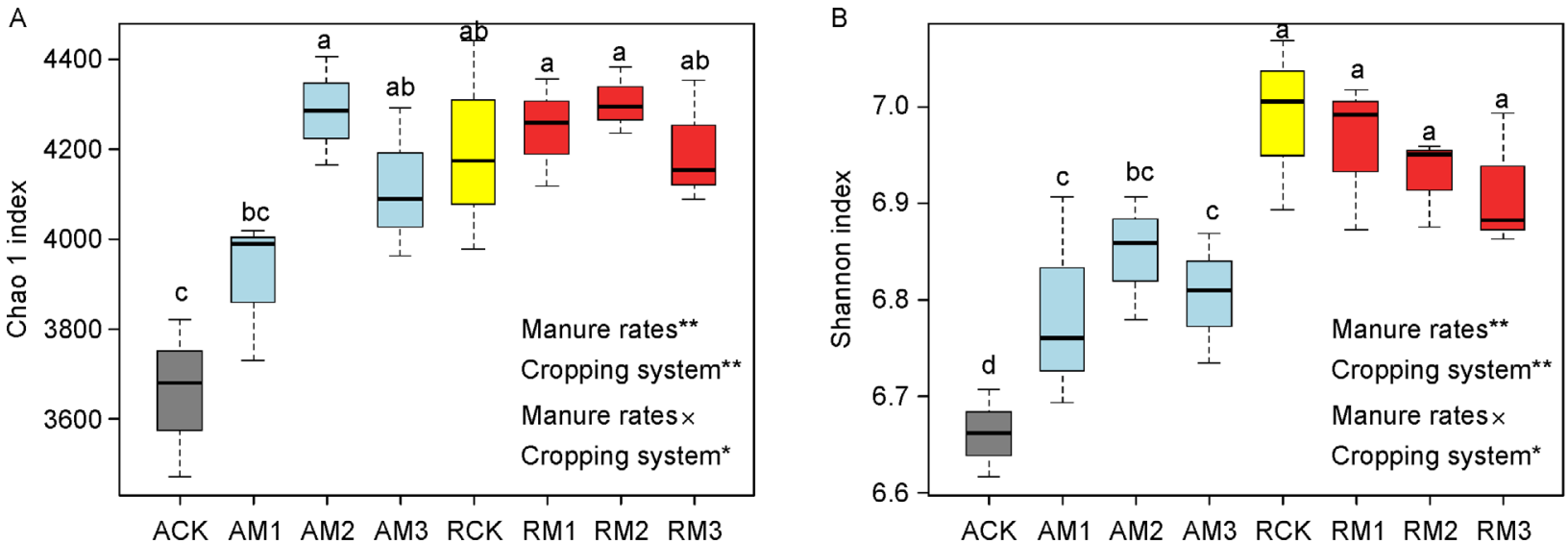

Fig. 1 Alpha-diversity measurements of Chao $1(A)$ and Shannon index $(B)$ in control treatment $(C K)$ and with manure application rates of 1930, 3860 and $5790 \mathrm{~kg} \mathrm{ha}^{-1}(\mathrm{M} 1, \mathrm{M} 2$ and $\mathrm{M} 3$, respectively) in rape $(A)$ and rice $(\mathrm{R})$ seasons. Different letters indicate significant differences $(P<0.05)$ based on the analysis of variance. Also, the effects of manure rates, cropping system and their interactions on the bacterial $\alpha$-diversity were calculated by sequential ANOVA. ${ }^{*}$, ${ }^{* *}$, and ${ }^{* * *}$ mark significance at $P<0.05$, 0.01 , and 0.001 , respectively.

effect on the Chao 1 index in the rice season (Fig. 1A). In addition, the Shannon index in the CK and M1 treatments during the rice season was significantly $(P<0.05)$ higher than that during the rape season (Fig. 1B). The Chao 1 index was significantly $(P<0.05)$ affected by manure rates, cropping system and the interactions between these two factors, while the Shannon index was significantly $(P<0.05)$ affected by the cropping system and the interactions between manure rates and cropping system (Fig. 1).

Proteobacteria $(31 \%-41 \%)$, Chloroflexi $(18 \%-21 \%)$ and Acidobacteria $(11 \%-14 \%)$ were the dominant phyla across treatments (Fig. 2). The relative abundance of Proteobacteria in the rice season increased significantly from $36.2 \%$ in CK to $41.3 \%$ in M3 $(P<0.05)$, and small but not significant increases were observed in the M1 and M2 treatments compared with CK $(P=0.159)$. In the rape season, the relative abundance of Proteobacteria increased significantly $(P<0.05)$ from $31.0 \%$ in $\mathrm{CK}$ to $35.8 \%, 36.6 \%$ and $38.4 \%$ in the $\mathrm{M} 1, \mathrm{M} 2$ and $\mathrm{M} 3$ treatments, respectively. The relative abundance of Chloroflexi in the rape season exhibited a small but not significant $(P$ $=0.223$ ) increase with the increase in the manure application rate. The relative abundance of Bacteroidetes increased first and then decreased with increasing amounts of manure and reached the highest abundances of $8.7 \%$ and $5.4 \%$ in the rice and rape seasons, respectively. Furthermore, Bacteroidetes abundance in the rape season was lower than that in the rice season. M2 and M3 significantly $(P<0.05)$ increased the relative abundance of Actinobacteria from $2.8 \%$ in CK to $4.0 \%$ in the rice season and from $2.6 \%$ in $\mathrm{CK}$ to $6.0 \%$ in the rape season. In contrast, long-term manure application led to a decrease in the relative abundances of Nitrospirae, Latescibacteria and Chlorobi. Specifically, the relative abundance of Nitrospirae decreased significantly $(P<0.01)$ from $7.8 \%$ and $13.0 \%$ in CK to approximately $4.0 \%$ in the M3 treatment during the rice and rape seasons, respectively. Similarly, the relative abundance of Chlorobi decreased significantly $(P<0.01)$ from $0.8 \%$ and $1.2 \%$ in $\mathrm{CK}$ to $0.5 \%$ and $0.3 \%$ in the $\mathrm{M} 3$ treatment during the rice and rape seasons, respectively.

Hydrogenophilaceae (14\%-21\%), Nitrosomonadaceae $(10 \%-15 \%)$ and Xanthomonadaceae $(7 \%-11 \%)$ were the three most abundant families in Proteobacteria across all treatments (Fig. 3). Manure application increased the relative abundance of Hydrogenophilaceae in all treatments except for M2 in the rice season, but there was no significant difference among treatments $(P=0.256$ and 0.260 in the rice and rape seasons, respectively). In the rice season, the M2 and M3 treatments significantly $(P<0.05)$ increased the relative abundances of Nitrosomonadaceae and Rhodospirillaceae compared with those in CK, while the relative abundances of Xanthomonadaceae and Syntrophaceae significantly $(P<0.05)$ decreased. Manure amendment increased the relative abundance of Acidiferrobacteraceae from $1.23 \%$ in $\mathrm{CK}$ to $5.3 \%, 6.6 \%$ and $8.6 \%$ in $\mathrm{M} 1, \mathrm{M} 2$ and $\mathrm{M} 3$ treatments, respectively (Fig. 3A). For the rape season, longterm application of manure increased the relative abundances of Nitrosomonadaceae, Acidiferrobacteraceae, Rhodospirillaceae and Hyphomonadaceae, especially Acidiferrobacteraceae, which increased significantly $(P<0.05)$ by $2.8,4.6$ and 4.8 times in M1, M2 and M3 compared with CK, respectively. However, the relative abundances of Gallionellaceae and Syntrophorhabdaceae decreased with manure application, especially Gallionellaceae, which decreased significantly $(P<0.05)$ from $17.5 \%$ in $\mathrm{CK}$ to $8.6 \%, 5.8 \%$ and $3.5 \%$ in the M1, M2 and M3 treatments, respectively (Fig. 3B).

\subsection{Specific bacterial taxa modulated by manure application}

LEfSe analysis from the phylum to the genus level was used to find the representative biomarkers (specific abundant taxa) of the different treatments during the rice and rape seasons 


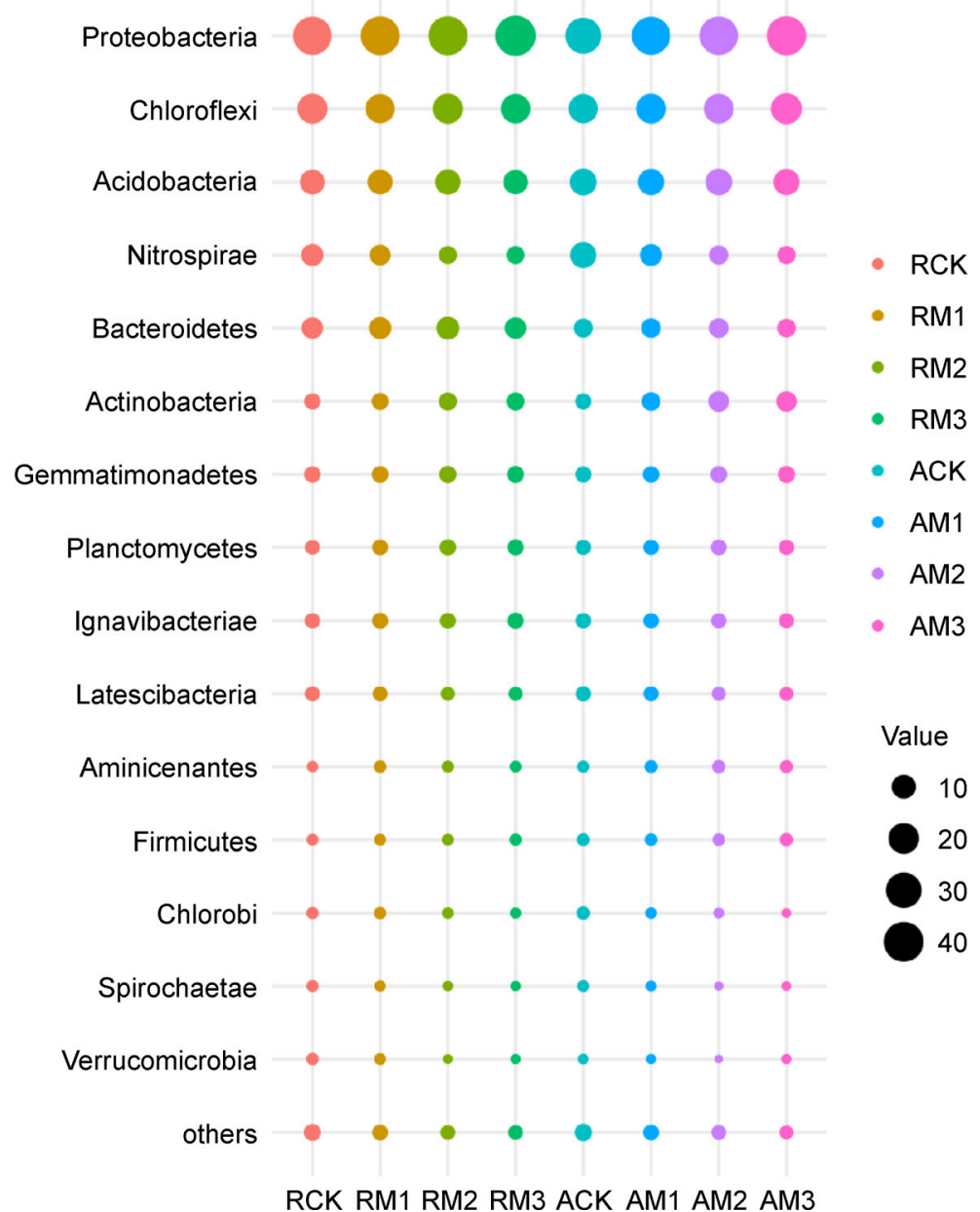

Fig. 2 Relative abundance of the soil bacterial community composition at the phylum level. Bubble size corresponds to the relative abundance. All other designations are the same as those in Fig. 1.

(Fig. 4). A total of 41 and 67 bacterial taxa with LDA scores of $>3$ were selected as biomarkers of the different treatments in the rice and rape seasons, respectively (Fig. S1). Specifically, in the rice season, Spirochaetae and Nitrospirae at the phylum level and Spirochaetes, Nitrospira and Pseudolabrys at the genus level were enriched in the CK treatments. Desulfobacterales and Syntrophobacterales at the order level and Desulfobulbus at the genus level were enriched in the $M 1$ and $M 2$ treatments. Micrococcales, Rhodocyclales and Pseudomonadales were also enriched in the M2 treatments. In the M3 treatment, Gammaproteobacteria, Actinobacteria and Planctomycetales at the phylum level and Nitrosomonadaceae, Planctomycetaceae, Rhodospirillaceae at the family level were enriched (Fig. 4A and Fig. S1a). For the rape season, Nitrospirae, Latescibacteria, Spirochaetae and Armatimonadetes at the phylum level and Nitrospira, Sideroxydans and Pseudolabrys at the genus level were enriched in the CK treatments. Desulfobulbaceae and Syntrophobacterales were enriched in the M1 treatment, and Actinobacteria, Saprospiraceae and Acidimicrobiales predominated in the M2 treatment (Fig. 4B and Fig. S1b). In the M3 treatment during the rape season, Xanthomonadales, Acid- iferrobacter, Pseudomonadales, Moraxellaceae and Acinetobacter belonging to Gammaproteobacteria were enriched. The bacterial lineages from Flavobacteriia (class) to Flavobacterium (genus) were also enriched in the M3 treatment (Fig. 4B and Fig. S1b).

3.4 Effect of environmental variables on bacterial community

Pearson correlation analysis indicated close relationships between the $\alpha$-diversity and edaphic variables (Table S1). The Chao 1 index was significantly positively correlated with soil $\mathrm{pH}(r=0.772, P<0.01), \mathrm{TC}(r=0.793, P<0.01), \mathrm{TN}(r=0.760$, $P<0.01)$, AP $(r=0.835, P<0.01)$, AK $(r=0.670, P<0.05)$ and $\mathrm{NH}_{4}{ }^{+}-\mathrm{N}(r=0.637, P<0.05)$ but negatively correlated with $\mathrm{C} / \mathrm{P}$ $(r=-0.849, P<0.001)$ and N/P $(r=-0.856, P<0.001)$ in the rape season. In the rice season, there were significantly negative correlations between the Shannon index and $\mathrm{pH}(r=$ $-0.674, P<0.05)$, TC $(r=-0.832, P<0.01)$, TN $(r=-0.697$, $P<0.05)$ and AP $(r=-0.872, P<0.001)$ but positive correlations with $\mathrm{C} / \mathrm{P}(r=0.850, P<0.001)$ and N/P $(r=0.822$, $P<0.001)$. In contrast, soil pH $(r=0.744, P<0.01)$, TC $(r=$ $0.694, P<0.05)$, TN $(r=0.650, P<0.05)$ and AP $(r=0.712$, 

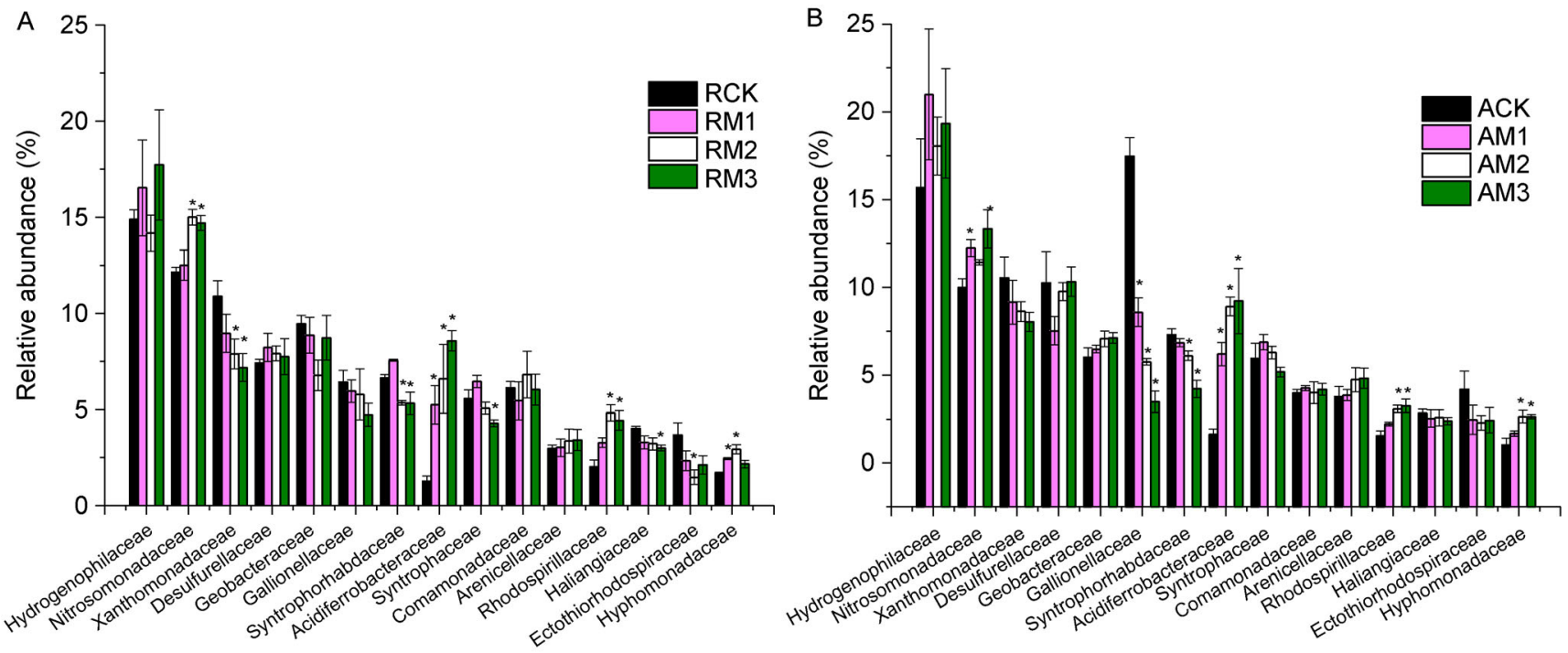

Fig. 3 Relative abundance of the 15 most abundant bacterial proteobacteria families in rice (A) and rape (B) seasons. Each stripe represents the mean of three replicates and error bars represent the standard errors of the triplicate values. ${ }^{*}$ mark represents significant differences at $P<0.05$ compared with $\mathrm{CK}$.

A

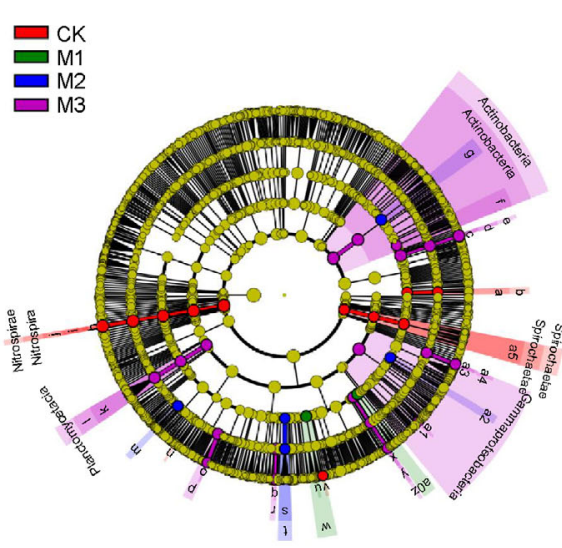

B

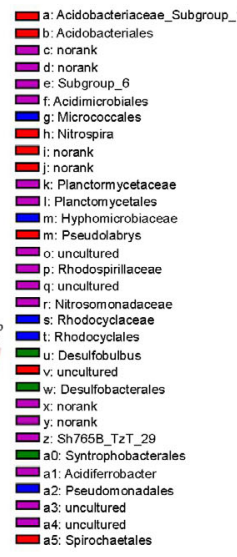

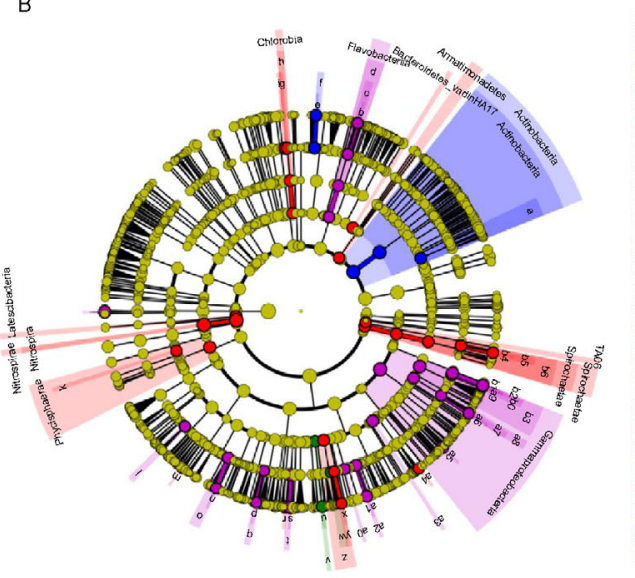

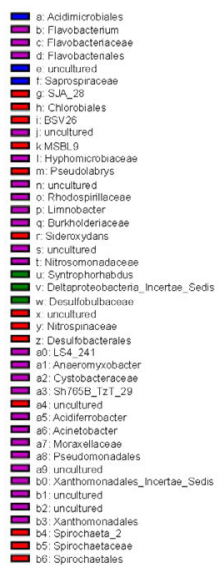

Fig. 4 Linear discriminant effect size analysis cladogram of comparison results among different treatments in rice $(A)$ and rape (B) seasons. Red, green, blue and purple circles stand for taxa that were abundant in the CK, M1, M2 and M3 treatments, respectively. Only taxa meeting a linear discriminant analysis significance threshold of 3 were shown. The six rings of the cladogram stand for domain (innermost), phylum, class, order, family, and genus.

$P<0.01)$ were significantly positively correlated with the Shannon index, but C/P $(r=-0.767, P<0.01)$ and N/P $(r=$ $-0.774, P<0.01$ ) were significantly negatively correlated with the Shannon index in the rape season (Table S1).

PCoA revealed that more than half of the variation in the bacterial community could be explained by the first two principal coordinates, with the first principal coordinate axis accounting for approximately $37 \%$ of the total variation and the second accounting for approximately $14 \%$ (Fig. 5A). Samples from manure treatments were separated from those from the CK treatment in the rice and rape seasons along the first principal coordinate axis. However, samples from the M2 and M3 treatments were close to each other, especially in the rice season. Furthermore, soil samples from the rice and rape seasons in the corresponding treatments were separated on the second axis (Fig. 5A). PERMANOVA further showed that 

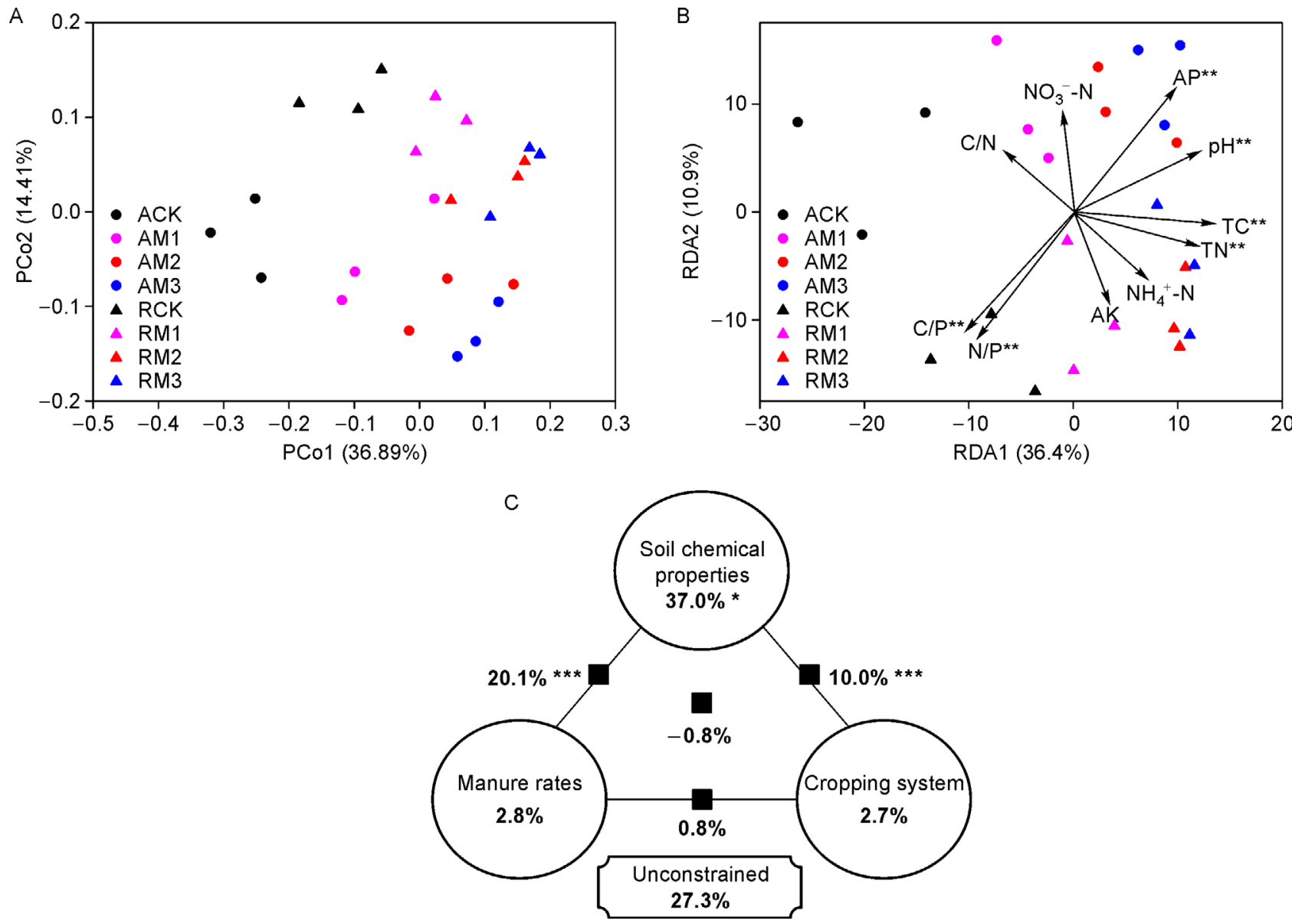

Fig. 5 (A) Principal coordinate analysis (PCoA) of total soil microbial community based on the Bray-Curtis distance. (B) Redundancy analysis (RDA) ordination plots quantifying the impacts of edaphic factors on soil bacterial community structure. Double asterisks represent significance at $P<0.01$, based on 999 Monte Carlo permutations (C) Variance partitioning analysis (VPA) map of the effects of soil chemical properties, manure rates, cropping system, and the interactions of these factors on the microbial community. One and three asterisks represent significance at $P<0.05$ and $P<0.001$, respectively.

rice and rape seasons and different manure application rates, except for the M2 and M3 treatments, had significant effects on soil bacterial communities (Table 2). RDA was performed to examine the associations between edaphic factors and bacterial communities (Fig. 5B). The distribution of different treatments in the RDA was similar to that in the PCoA. All measured soil physicochemical properties were significantly correlated with the bacterial community $(P<0.05)$. Among those factors, soil $\mathrm{pH}, \mathrm{TC}, \mathrm{TN}, \mathrm{AP}, \mathrm{C} / \mathrm{P}$ and N/P ratios exhibited great correlations with the bacterial community $(P<0.01)$ (Fig. 5B). Additionally, BIO-ENV analysis showed the best correlations of $\mathrm{pH}, \mathrm{TC}, \mathrm{C} / \mathrm{P}$ and $\mathrm{N} / \mathrm{P}$ to the soil bacterial community, and soil $\mathrm{C} / \mathrm{P}$ was the most important factor shaping bacterial community (Table 3). VPA was carried out to quantify the relative contributions of soil properties (Table 1), manure rates and the cropping system and the interactions between these factors to the soil bacterial communities (Fig. 5C). These variables explained $72.7 \%$ of the observed variation, and $27.3 \%$ of the variation was unexplained. Of these independent variables, soil chemical properties exhibited the largest significant impact on the soil microbial taxonomic profile $(37 \%)(P<0.05)$, followed by the cropping system (2.7\%) and manure rates (2.8\%) (Fig. $5 \mathrm{C})$.

Soil $\mathrm{pH}, \mathrm{TC}, \mathrm{TN}$ and AP exhibited significant and positive correlations (Spearman's test $(\rho>0.6, P<0.001))$. The $C / P$ and N/P ratios were strongly and negatively correlated $(\rho>$

Table 2 The effects of manure rates and cropping system on the bacterial community structure tested by permutational multivariate analysis of variance (PERMANOVA) using Bray-Curtis distance metrics.

\begin{tabular}{lll}
\hline & $R^{2}$ & $P$ \\
\hline Rice $\times$ Rape & 0.1524 & 0.003 \\
$\mathrm{CK} \times \mathrm{M} 1$ & 0.234 & $\mathbf{0 . 0 1 6}$ \\
$\mathrm{CK} \times \mathrm{M} 2$ & 0.382 & $\mathbf{0 . 0 0 5}$ \\
$\mathrm{CK} \times \mathrm{M} 3$ & 0.447 & $\mathbf{0 . 0 0 1}$ \\
$\mathrm{M} 1 \times \mathrm{M} 2$ & 0.156 & $\mathbf{0 . 0 3 4}$ \\
$\mathrm{M} 1 \times \mathrm{M} 3$ & 0.221 & $\mathbf{0 . 0 0 2}$ \\
$\mathrm{M} 2 \times \mathrm{M} 3$ & 0.079 & 0.581 \\
\hline
\end{tabular}

The significant variations are shown in bold. 
Table 3 BIO-ENV analysis based on the Speraman's rank correlation coefficient $(\rho)$, showing the association between soil bacterial community and environmental variables.

\begin{tabular}{lc}
\hline Combined variables & Spearman's coefficient $(\rho)$ \\
\hline $\mathrm{C} / \mathrm{P}$ & 0.6941 \\
$\mathrm{TC}+\mathrm{C} / \mathrm{P}$ & 0.7459 \\
$\mathrm{TC}+\mathrm{C} / \mathrm{P}+\mathrm{N} / \mathrm{P}$ & 0.7621 \\
$\mathrm{pH}+\mathrm{TC}+\mathrm{C} / \mathrm{P}+\mathrm{N} / \mathrm{P}$ & 0.7647 \\
$\mathrm{pH}+\mathrm{TC}+\mathrm{NO}_{3}{ }^{-} \mathrm{N}+\mathrm{C} / \mathrm{P}+\mathrm{N} / \mathrm{P}$ & 0.7571 \\
$\mathrm{pH}+\mathrm{TC}+\mathrm{AP}+\mathrm{NO}_{3}{ }^{-}-\mathrm{N}+\mathrm{C} / \mathrm{P}+\mathrm{N} /$ & 0.7472 \\
$\mathrm{P}$ & \\
$\mathrm{pH}+\mathrm{TC}+\mathrm{TN}+\mathrm{AP}+\mathrm{NO}_{3}{ }^{-}-\mathrm{N}+\mathrm{C} / \mathrm{P}$ & 0.7399 \\
$+\mathrm{N} / \mathrm{P}$ & \\
$\mathrm{pH}+\mathrm{TC}+\mathrm{TN}+\mathrm{AP}+\mathrm{NO}_{3}{ }^{-}-\mathrm{N}+\mathrm{C} / \mathrm{P}$ & 0.6524 \\
$+\mathrm{C} / \mathrm{N}+\mathrm{N} / \mathrm{P}$ & \\
\hline
\end{tabular}

$-0.6, P<0.001)$ with soil $\mathrm{pH}, \mathrm{AP}$ and $\mathrm{NO}_{3}{ }^{-}-\mathrm{N}$ (Fig. 6A). The Mantel test showed that soil $\mathrm{pH}, \mathrm{TC}, \mathrm{TN}, \mathrm{AP}, \mathrm{C} / \mathrm{P}$ and $\mathrm{C} / \mathrm{P}$ had significant effects $(P<0.01)$ on the composition of the soil bacterial community (Fig. 6A). Furthermore, we used multiple regression modeling to evaluate the biological associations of the main microbiota at the phylum level with variations in soil physicochemical properties (Fig. 6B). We found that most of the determined soil factors contributed to the variations in soil bacterial communities. The relative abundances of Proteobacteria and Actinobacteria showed significantly positive correlations with soil $\mathrm{pH}$ and $\mathrm{TC}(P<0.05)$ and Proteobacteria was also significantly correlated with TN content $(P<0.01)$. On the contrary, the relative abundance of Nitrospirae was significantly negatively correlated with soil $\mathrm{pH}, \mathrm{TC}, \mathrm{TN}$ and $\mathrm{AP}$ $(P<0.01)$ (Fig. 6B). Additionally, the soil C/P and N/P ratios exhibited significantly positive correlations with the abundances of Nitrospirae, Latescibacteria, Chlorobi, Spirochae- tae and Verrucomicrobia but negative correlations with the abundances of Actinobacteria and Aminicenantes $(P<0.05)$ (Fig. 6B).

\subsection{Co-occurrence networks}

To explore the complexity of bacterial connections and the associations among OTUs and soil properties, co-occurrence network analysis was performed (Fig. 7 and Fig S2). The cooccurrence networks of bacterial communities were markedly different between the $\mathrm{CK}$ and manure treatments. In general, the number of correlations in the M1 treatment was substantially higher than those in the $\mathrm{CK}, \mathrm{M} 2$ and $\mathrm{M} 3$ treatments (Fig. 7 and Table S2). The bacterial community exhibited 796 significant associations (edges) with 693 nodes in CK, 1022 edges with 1052 nodes in the M1 treatment, 253 edges with 360 nodes in the M2 treatment and 218 edges with 302 nodes in the M3 treatment (Table S2). The networks of CK, M1 M2 and M3 exhibited 2.297, 1.943, 1.406 and 1.444 neighbors on average and characteristic path lengths of 4.654, 7.191, 1.202 and 2.021 respectively (Table S2). With respect to rice season and rape season, the network of rape season had higher nodes and edges in comparison with rice season (Table S2). The dominant identifiable OTUs in all treatments belonged to Proteobacteria, Chloroflexi and Acidobacteria (Fig. 7 and Fig. S2).TC, TN, pH, C/N, C/P and N/P tended to be more connected with bacterial taxa than other factors (Fig. S2c). For example, TC showed strong positive associations with Anaerolineaceae and two Acidobacteria members and negative associations with Nitrospira, one Verrucomicrobia member, Ferruginibacter, and one Ignavibacteriae member. TN showed strong positive associations with one Acidobacteria member and one Gemmatimonadetes member, while it was negatively associated with
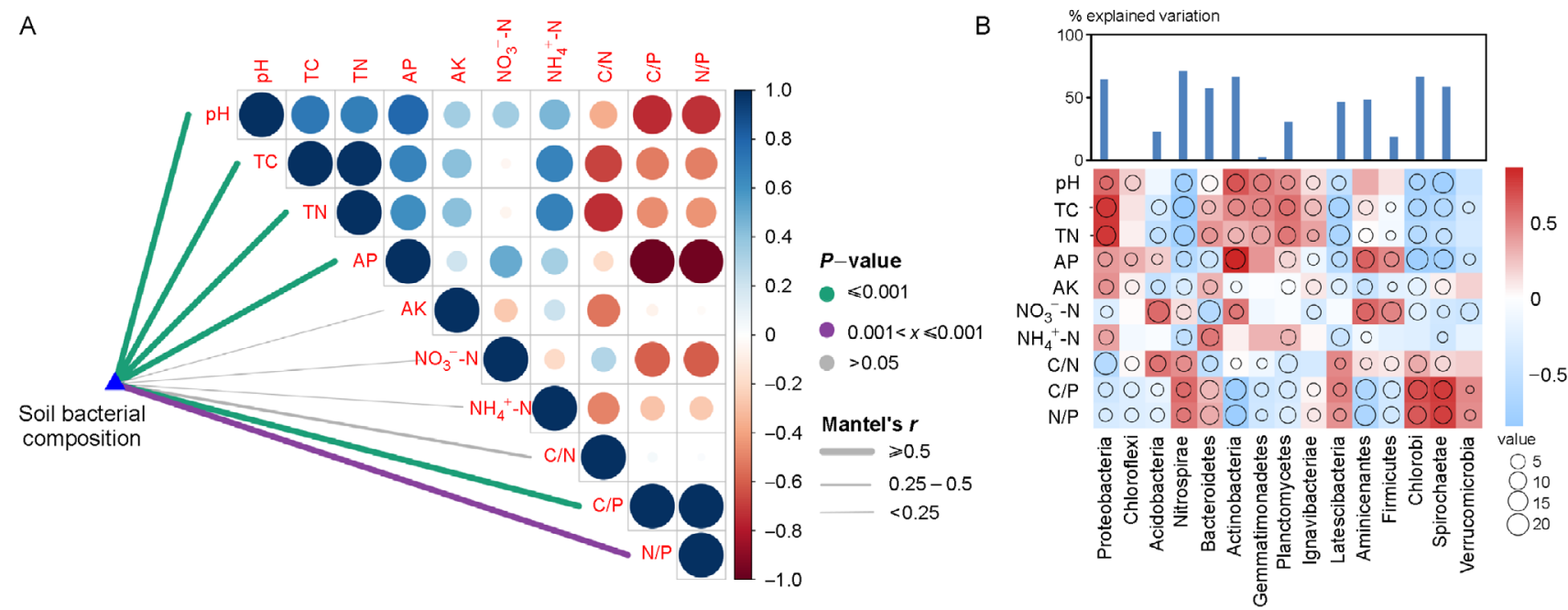

Fig. 6 Relationships between edaphic variables and soil bacterial community. (A) Pairwise comparisons of edaphic variables were displayed with a color gradient denoting Spearman's correlation coefficients. Taxonomic groups were related to each environmental factor by Mantel test. (B) Correlation and best random forest model for major taxonomic (phylum) of soil bacteria. Circle size represents the variable's importance (i.e., proportion of explained variation calculated via multiple regression modeling). Colors represent Spearman correlations. 

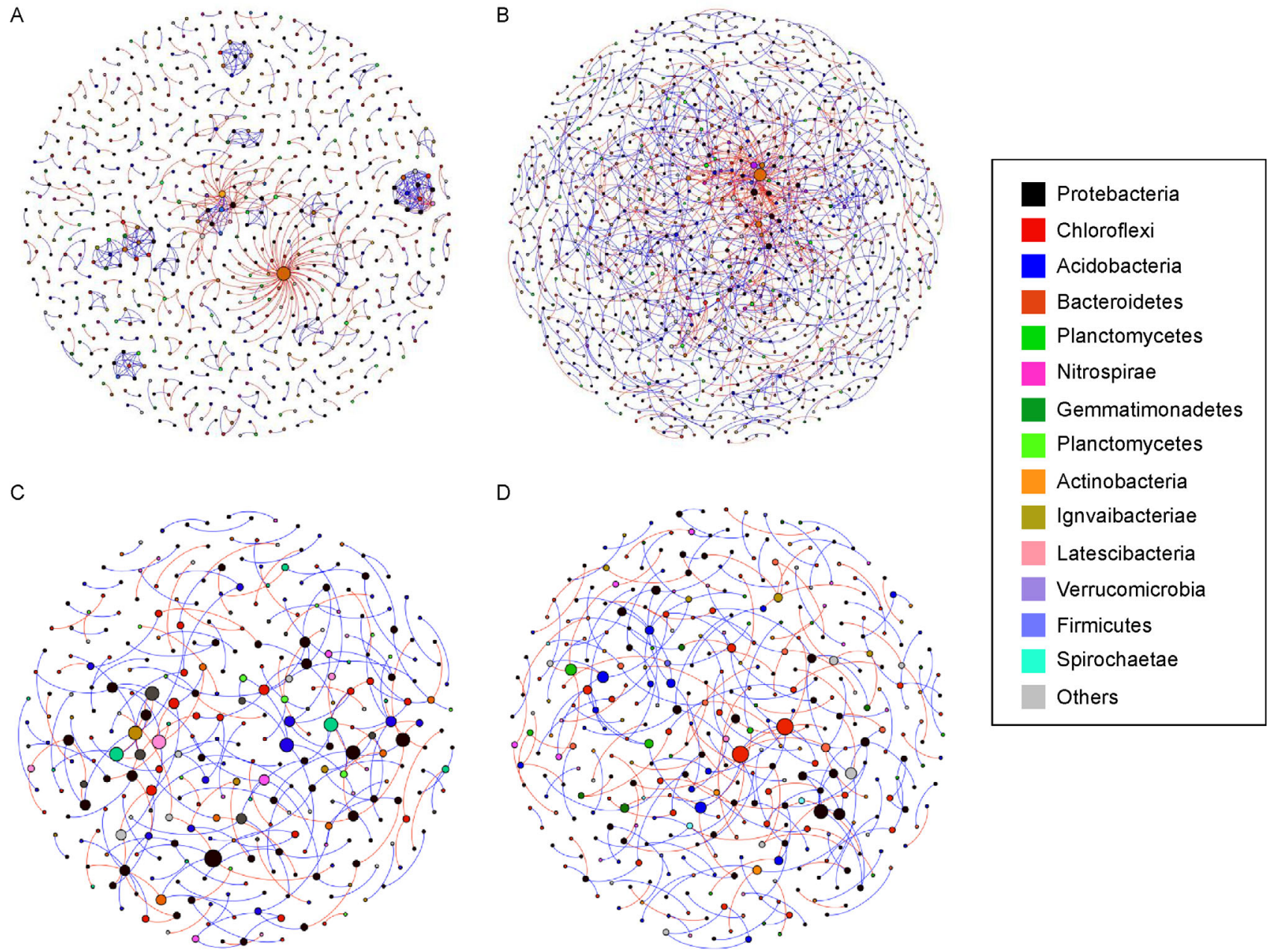

Fig. 7 Network analysis revealing the associations among bacterial OTUs in CK (A), M1 (B), M2 (C) and M3 (D). Blue line and red line represent strong positive linear $(r>0.8)$ and strong negative linear $(r<-0.8)$ and relationships, respectively. Colored nodes signify corresponding OTUs assigned to major phyla. The size of each node is proportional to the number of connections (that is, degree).

Nitrospira. One Acidobacteria member, Geobacter and Nitrospira were positively associated with $\mathrm{pH}$. One member in Hydrogenophilaceae was positively associated with AP. In addition, $\mathrm{C} / \mathrm{N}$ showed strong positive associations with Roseiflexus, two Acidobacteria members and Geobacter. $\mathrm{C} / \mathrm{P}$ and N/P had significantly negative associations with one Aminicenantes member and Hydrogenophilaceae (Fig. S2c).

\section{Discussion}

4.1 Effects of manure fertilization and crop rotation on bacterial diversity

The results of the present study demonstrated that soil physicochemical properties were significantly changed after 9 years of manure application in rice and rape seasons. Manure fertilization induced increases in soil nutrients (i.e., TC, TN, TP and available $\mathrm{P}$ ) and soil $\mathrm{pH}$, which was generally consistent with the results of previous studies (Zhong et al., 2010; Wang et al., 2017; Liu et al., 2018). Thus, organic fertilizers would be essential to improve soil fertility. Long-term manure application increased the bacterial richness and diversity in the rape season (Fig. 1), which was consistent with the results of previous studies in upland soils amended with organic fertilizer (Ge et al., 2008; Hartmann et al., 2015; Sun et al., 2015). The increases in soil $\mathrm{pH}$ and nutrient contents were suggested to be significant factors for increasing bacterial diversity (Table S1) (Ding et al., 2016; Yang et al., 2017). However, this phenomenon was observed in only the rape season and not in the rice season in the present study (Table S1 and Fig. 1). In addition, the cropping system was found to have a significant effect on soil bacterial diversity, especially on the Shannon index (Fig. 1), which was in agreement with the results of previous studies (Acosta-Martínez et al., 2008; Zhao et al., 2014). The specific root exudates and litter of plant and soil water dynamic changes may cause the differences in 
bacterial diversity in rice and rape seasons (Venter et al., 2016). There was no significant difference in bacterial diversity in the rice season, and similar findings are observed in paddy soil (Wu et al., 2011; Yang et al., 2019). Soil planted with rice often experiences alterations of flooding and drying (Wang et al., 2017), which would have greater influence on bacterial diversity than fertilizer, and consequently effects bacterial diversity. However, there was a decreasing tendency of bacterial diversity under a high load of manure (M3) (Fig. 1B). Pig manure contains high levels of antibiotics (Zhao et al., 2010), which might inhibit the influence of manure application on soil bacterial diversity. In addition, the high availability of rich substrate with a high manure application rate would promote the growth of copiotrophic organisms, whose predominance in turn reduced the diversity. A decreased bacterial diversity may lead to a less stable ecosystem (Chaer et al., 2009), and in this sense, very high manure application is not suitable for sustainable microbial processes and functions and increases the environmental risk.

4.2 Effects of manure fertilization and crop rotation on bacterial composition

Proteobacteria, Chloroflexi and Acidobacteria were the dominant phyla across all treatments (Fig. 2), which was in agreement with the results of previous studies on different fertilization regimes (Zhou et al., 2015; Li et al., 2017; Kumar et al., 2018). PCoA showed that the manure treatments (M1, $\mathrm{M} 2$ and $\mathrm{M} 3$ ) were separated from the control on the first PCoA axis, and the treatments during the rice and rape seasons were separated along the second axis (Fig. 5A). That indicated both long-term manure application and crop rotation changed the soil bacterial community composition, and the impact of manure application was more obvious. Soil microbial community may retain certain legacy effects from long-term crop rotation (Soman et al., 2017). Long-term manure application significantly increased the growth of Proteobacteria and Actinobacteria (Fig. 2), which was supported by a meta-analysis (Dai et al., 2018) and other field studies (Wang et al., 2017b; Chen et al., 2018). LEfSe analysis also proved that Gammaproteobacteria and Actinobacteria were the abundant taxa in the M3 treatment in the rice season and M2 and M3 treatments in the rape season (Fig. 4). Proteobacteria are involved in the bio-recycling of essential mineral nutrients (Lesaulnier et al., 2008), and a high proportion of Proteobacteria may contribute to improving soil fertility and even plant growth (Chaudhry et al., 2012). For example, Nitrosomonadaceae and Acidiferrobacteraceae, which are members of the phylum Proteobacteria and are involved in $\mathrm{N}$ and sulfur cycles (Prosser et al., 2014; Umezawa et al., 2016), were enriched in the manure treatments (Fig. 3). Most bacteria in the Proteobacteria and Actinobacteria phyla are copiotrophic bacteria and prefer to live in nutrient-sufficient environments (Newton and McMahon, 2011; Dai et al., 2018). The positive correlations of Proteobacteria and Actinobacteria with TC and TN (Fig. 6B) were also suggested that. Thus, the high TC and TN contents in the manure treatments (Table 1) could result in the enrichment of copiotrophic microbes. However, long-term manure application, especially at high doses, significantly decreased the relative abundance of Nitrospirae, which showed significant negative correlations with TC and TN (Fig. 6B) and was in accordance with the enrichment of Nitrospirae and Nitrospira in CK indicated by LEfSe analysis (Figs. 2 and 4). Similar observations were found in some previous studies (Zhou et al., 2015; Yang et al., 2019). Nitrospira, the main genus within Nitrospirae, have been described as K-strategists favoring low $\mathrm{N}$ availability (Attard et al., 2010). The low relative abundance of Nitrospirae at the high manure amendment rate indicated that there might be reduced nitrification activity and less $\mathrm{N}$ loss due to soil nitrification.

There is the possibility that exogenous bacteria from manure would contribute to altering soil bacterial community (Watts et al., 2010). However, some studies prove the effect of introduced bacteria from manure on soil bacteria community can be negligible (Chu et al., 2007; Li et al., 2017). A plausible explanation is that the most bacteria in manure which are well adapted to the gut environments are less competitive than indigenous microorganisms in soil (Sun et al., 2015). No significant difference of Chao 1 and Shannon index among $\mathrm{CK}$ and manure treatments in the rice season (Fig. 1) suggested bacteria in manure had negligible effect on soil bacterial diversity. Besides, the abundant bacteria taxa in pig manure are Firmicutes, Bacteroidetes and Actinobacteria (Sun et al., 2015). However, the relative abundances of Firmicutes and Actinobacteria were of no significant differences between $\mathrm{CK}$ and manure treatments in rice and rape seasons. The relative abundance of Bacteroidetes even decreased in M3 treatments (Fig. 2). VPA analysis suggested soil properties other than manure rates had significant effect on soil bacterial community (Fig. 5C). Therefore, our data indicated that the long-term application of manure alters soil bacterial community mainly through changing soil properties, rather than the exogenous bacteria input.

4.3 The relationships between soil properties and bacterial communities

The chemical properties of soil appeared to be a statistically significant determinant of the structure of soil microbial communities (Lauber et al., 2008; Ling et al., 2016; Zhang et al., 2017). VPA analysis indicated that soil properties (37\%) had an independent and significant influence on the soil microbiome (Fig. 5C). Among all determined soil properties, $\mathrm{pH}, \mathrm{TC}, \mathrm{TN}, \mathrm{AP}, \mathrm{C} / \mathrm{P}$ and N/P showed extremely significant effects $(P<0.01)$ on bacterial communities according to the Mantel test (Fig. 6A). In addition, pH, TC, C/P and N/P were the best combination to indicate the variations in soil bacterial communities (Table 3). Soil pH is usually considered to be the major factor influencing the bacterial community composition in various soils (Rousk et al., 2010; Griffiths et al., 2011; Liu et al., 2014; Zhang et al., 2017). Manure rates and cropping systems influenced the soil chemical properties at the same 
sites (Table 1) that shared similar soil types. It is widely accepted that long-term manure application could alleviate soil acidification and even improve soil pH (Noble et al., 1996; Cai et al., 2015), which would be an important factor shaping the soil microbial community. Soil TC and TN contents are also important factors for explaining the variations in the soil bacterial community during long-term fertilization trials ( $\mathrm{Li}$ et al., 2017; Ji et al., 2018) and large-scale studies (Liu et al., 2014). The addition of exogenous organics would induce the growth and reproduction of some microbial taxa, which would promote the decomposition of organics under appropriate $\mathrm{C}$ and $\mathrm{N}$ stoichiometric ratios (Li et al., 2017). In addition, some oligotrophs are stimulated by manure amendment to mineralize recalcitrant soil organic matter (SOM) using fresh organics as an energy source, causing a short-term change in SOM turnover (the priming effect) (Blagodatskaya and Kuzyakov, 2008). In addition, manure fertilizer, as a type of $C$ source for microbes, can improve environmental conditions considering the dependence of microbial communities on resource quality and availability (Helgason et al., 2010). Therefore, soil $\mathrm{C}$ and $\mathrm{N}$ have a close connection with soil bacterial communities under long-term manure application. Furthermore, soil available $\mathrm{P}$ also had a significant correlation with the bacterial community, which was consistent with previous studies (Ding et al., 2016; Yang et al., 2017). Interestingly, C/P and N/P stoichiometric ratios had extreme effects on the bacterial communities, which were usually ignored. Our results showed that the soil C/P and N/P ratios, but not the $\mathrm{C} / \mathrm{N}$ ratio, had significant effects on the bacterial $\alpha$ and $\beta$-diversities after long-term manure application, and similar results were found in a long-term fertilization study (Shen et al., 2019). This result may indicate that the soil $P$ content was more important than the $\mathrm{N}$ content in shaping bacterial communities. The distribution of the dominant phyla was significantly related to the soil N/P and C/P ratios (Fig. $6 \mathrm{~B}$ ). Additionally, most bacteria have high $\mathrm{P}$ demands to synthesize rRNA for growth according to the growth-rate hypothesis (Sterner and Elser, 2002). Thus, the relative abundances of these bacterial taxa were sensitive to changes in the soil $\mathrm{C} / \mathrm{P}$ and N/P ratios. Therefore, our results further prove that soil N/P and C/P stoichiometric ratios are tightly coupled with the composition of the soil bacterial community. In addition, there were significant interactions between soil chemical properties and manure rates $(20.1 \%)$ and the cropping system $(10.0 \%)$, indicating that these three factors exhibited close interactions and that the differences in bacterial communities were a result of the comprehensive effect of all factors rather than a single factor.

Network analysis showed TC showed the most connections with bacteria among all determined factors (Fig. S2c). For example, Anaerolineaceae and two Acidobacteria members were positively associated with TC. Anaerolineaceae members can cooperate syntrophically with methanogens for the decomposition of organic matters in anerobic conditions (Liang et al., 2015), and the micro-anaerobic environments caused by the decomposition of higher organic $C$ would be favorable for Anaerolineaceae growth. Some Acidobacteria members are abundant in soils with high SOC (Liu et al., 2014; $\mathrm{Li}$ et al., 2017) and have the ability to decompose organic matter (Rawat et al., 2012; Tveit et al., 2014). However, Nitrospira, which grow autotrophically, are nitrite-oxidizing bacteria for the second step of nitrification (Xia et al., 2011), thus, high TC would inhibit their growth. Verrucomicrobia, a bacterial taxon with oligotrophic characteristics (Carbonetto et al., 2014), was usually detected in low $C$ environments (Bergmann et al., 2011; Navarrete et al., 2015). Therefore, Nitrospira and Verrucomicrobia were significantly and negatively associated with soil TC.

\subsection{The interactions between bacteria}

Network graphs were constructed to represent the positive or negative interactions among bacterial OTUs and soil properties (Fig. 7 and Fig S2). A microbial community in soil amended with low amounts of manure (M1) had more ecologically similar functional groups (72 modules) than the soil with high manure addition (M2 and M3) (9 and 13 modules) and the CK treatment (34 modules) (Table S2), which was similar to the results of previous studies with organic fertilization (Ling et al., 2016; Wang et al., 2017). Bacterial members within a module are more connected and that they share similar ecological characteristics (Ling et al., 2016), and more modules in the microbial community suggest a higher degree of cooperation and exchange events in the ecosystem (Faust and Raes, 2012; Zhou et al., 2011). Additionally, the network with low manure amounts incorporated a substantially higher number of significant correlations than the other treatments (Fig. 7 and Table S2), indicating that soil microbial communities with low manure application rates were more complexly connected and potentially more stable. Similarly, the network in rape season incorporated a higher number of nodes, corrections and modules compared with rice season (Fig. S2 and Table S2), suggesting the interactions of soil microbial community were more complex in the rape season. This is probably because some aerobic bacteria were reactivated when growing rape. However, high manure application rates decreased the interactions between bacteria and the stability of the network (Fig. 7 and Table S2). A High manure dose enriches certain functional bacteria to decompose organics and change the bacterial community (Paul, 2014; Deng et al., 2016), as indicated by the decrease in bacterial diversity in the M3 treatment (Fig. 1B). A high load of manure decreases the degree of antagonism and weakens mutualism under eutrophic conditions (Sachs and Simms, 2006; Wang et al., 2017). Therefore, a low manure application rate could shape a more interactive bacterial community and improve the ability to resist external pressure.

\section{Conclusion}

Our results confirmed that different long-term manure application rates and crop rotation had significant effects on 
the soil bacterial community. Low manure application rate increased soil bacterial diversity in the rape season, while no significant differences were observed in the rice season among the manure treatments. However, high manure application rates tended to decrease bacterial diversity. Network analysis showed that higher manure application rates caused loose and unstable bacterial interactions compared with the CK and low manure application treatments. These results illuminate that low manure application rates are optimal for bacterial communities and that nutrient transformation and soil may be more active under these conditions. In addition, long-term manure application significantly altered the bacterial community composition, thus encouraging certain bacterial phyla (Proteobacteria and Actinobacteria) and reducing Nitrospirae. This study also implied that the soil bacterial community was closely related to the soil properties that were changed by manure amendment gradients and crop rotation, and $\mathrm{pH}, \mathrm{TC}, \mathrm{TN}, \mathrm{C} / \mathrm{P}$ and N/P play important roles in shaping bacterial communities. Therefore, our results may have significant implications for the development of better management practices for farm ecosystems.

\section{Acknowledgments}

This study was supported by the National Key Research and Development Program of China (2017YFD0800404), the National Natural Science Foundation of China (41671249), and Fundamental Research Funds for the Central Universities (2019QNA6011).

\section{Conflicts of interest}

The authors do not have any personal, financial, or other conflicts of interest with other people or organizations that could inappropriately influence, or be perceived to influence our work.

\section{Electronic supplementary material}

Supplementary material is available in the online version of this article at http://dx.doi.org/10.1007/s42832-020-0032-8 and is accessible for authorized users.

\section{References}

Acosta-Martínez, V., Dowd, S., Sun, Y., Allen, V., 2008. Tag-encoded pyrosequencing analysis of bacterial diversity in a single soil type as affected by management and land use. Soil Biology \& Biochemistry 40, 2762-2770.

Ai, C., Liang, G., Sun, J., Wang, X., He, P., Zhou, W., He, X., 2015. Reduced dependence of rhizosphere microbiome on plant-derived carbon in 32-year long-term inorganic and organic fertilized soils. Soil Biology \& Biochemistry 80, 70-78.

Attard, E., Poly, F., Commeaux, C., Laurent, F., Terada, A., Smets, B. F., Recous, S., Roux, X.L., 2010. Shifts between Nitrospira- and Nitrobacter-like nitrite oxidizers underlie the response of soil potential nitrite oxidation to changes in tillage practices. Environ- mental Microbiology 12, 315-326.

Bahram, M., Hildebrand, F., Forslund, S.K., Anderson, J.L., Soudzilovskaia, N.A., Bodegom, P.M., Bengtsson-Palme, J., Anslan, S., Coelho, L.P., Harend, H., Huerta-Cepas, J., Medema, M.H., Maltz, M.R., Mundra, S., Olsson, P.A., Pent, M., Põlme, S., Sunagawa, S., Ryberg, M., Tedersoo, L., Bork, P., 2018. Structure and function of the global topsoil microbiome. Nature 560, 233-237.

Bailey, K.L., Lazarovits, G., 2003. Suppressing soil-borne diseases with residue management and organic amendments. Soil \& Tillage Research 72, 169-180.

Bastian, M., Heymann, S., Jacomy, M., 2009. Gephi: an open source software for exploring and manipulating networks. ICWSM 8, 361362.

Benjamini, Y., Hochberg, Y.. 1995. Controlling the false discovery rate: a practical and powerful approach to multiple testing. Journal of the Royal Statistical Society 57, 289-300

Bergmann, G.T., Bates, S.T., Eilers, K.G., Lauber, C.L., Caporaso, J. G., Walters, W.A., Knight, R., Fierer, N., 2011. The underrecognized dominance of Verrucomicrobia in soil bacterial communities. Soil Biology \& Biochemistry 43, 1450-1455.

Blagodatskaya, E., Kuzyakov, Y., 2008. Mechanisms of real and apparent priming effects and their dependence on soil microbial biomass and community structure: critical review. Biology and Fertility of Soils 45, 115-131.

Brown, M.B., 1975. 400: a method for combining non-independent, one-sided tests of significance. Biometrics 31987-992

Cai, Z., Wang, B., Xu, M., Zhang, H., He, X., Zhang, L., Gao, S., 2015. Intensified soil acidification from chemical $\mathrm{N}$ fertilization and prevention by manure in an 18-year field experiment in the red soil of southern China. Journal of Soils and Sediments 15, 260270.

Caporaso, J.G., Kuczynski, J., Stombaugh, J., Bittinger, K., Bushman, F.D., Costello, E.K., Fierer, N., Peña, A.G., Goodrich, J.K., Gordon, J.I., Huttley, G.A., Kelley, S.T., Knights, D., Koenig, J.E., Ley, R.E., Lozupone, C.A., McDonald, D., Muegge, B.D., Pirrung, M., Reeder, J., Sevinsky, J.R., Turnbaugh, P.J., Walters, W.A., Widmann, J., Yatsunenko, T., Zaneveld, J., Knight, R., 2010. QIIME allows analysis of high-throughput community sequencing data. Nature Methods 7, 335-336.

Carbonetto, B., Rascovan, N., Álvarez, R., Mentaberry, A., Vázquez, M.P., 2014. Structure, composition and metagenomic profile of soil microbiomes associated to agricultural land use and tillage systems in Argentine Pampas. PLoS One 9, e99949.

Carson, P.L., 1980. Recommended potassium test. In: Dahnke, W.C., ed. Recommended Chemical Soil Test Procedures for the North Central Region. North Dakota Agricultural Experiment Station, Fargo, ND, pp. 17-18.

Cavagnaro, T.R., 2014. Impacts of compost application on the formation and functioning of arbuscular mycorrhizas. Soil Biology \& Biochemistry 78, 38-44.

Chaer, G., Fernandes, M., Myrold, D., Bottomley, P., 2009. Comparative resistance and resilience of soil microbial communities and enzyme activities in adjacent native forest and agricultural soils. Microbial Ecology 58, 414-424.

Chaudhry, V., Rehman, A., Mishra, A., Chauhan, P.S., Nautiyal, C.S., 2012. Changes in bacterial community structure of agricultural 
land due to long-term organic and chemical amendments. Microbial Ecology 64, 450-460.

Chen, Q.L., An, X.L., Zheng, B.X., Ma, Y.B., Su, J.Q., 2018. Long-term organic fertilization increased antibiotic resistome in phyllosphere of maize. Science of the Total Environment 645, 1230-1237.

Chu, H., Lin, X., Fujii, T., Morimoto, S., Yagi, K., Hu, J., Zhang, J., 2007. Soil microbial biomass, dehydrogenase activity, bacterial community structure in response to long-term fertilizer management. Soil Biology \& Biochemistry 39, 2971-2976.

Dai, Z., Su, W., Chen, H., Barberán, A., Zhao, H., Yu, M., Yu, L., Brookes, P.C., Schadt, C.W., Chang, S.X., Xu, J., 2018. Long-term nitrogen fertilization decreases bacterial diversity and favors the growth of Actinobacteria and Proteobacteria in agro-ecosystems across the globe. Global Change Biology 24, 3452-3461.

Deng, Y., Zhang, P., Qin, Y., Tu, Q., Yang, Y., He, Z., Schadt, C.W., Zhou, J., 2016. Network succession reveals the importance of competition in response to emulsified vegetable oil amendment for uranium bioremediation. Environmental Microbiology 18, 205-218.

Ding, J., Xin, J., Ma, M., Zhou, B., Guan, D., Zhao, B., Jing, Z., Cao, F., $\mathrm{Li}, \mathrm{L} ., \mathrm{Li}, \mathrm{J} ., 2016$. Effect of 35 years inorganic fertilizer and manure amendment on structure of bacterial and archaeal communities in black soil of northeast China. Applied Soil Ecology 105, 187-195.

Diniz-Filho, J.A.F., Soares, T.N., Lima, J.S., Dobrovolski, R., Landeiro, V.L., de Campos Telles, M.P., Rangel, T.F., Bini, L.M., 2013. Mantel test in population genetics. Genetics and Molecular Biology 36 , 475-485.

Edgar, R.C., 2010. Search and clustering orders of magnitude faster than BLAST. Bioinformatics (Oxford, England) 26, 2460-2461.

Edgar, R.C., Haas, B.J., Clemente, J.C., Quince, C., Knight, R., 2011. UCHIME improves sensitivity and speed of chimera detection. Bioinformatics (Oxford, England) 27, 2194-2200.

Faust, K., Raes, J., 2012. Microbial interactions: from networks to models. Nature Reviews. Microbiology 10, 538-550.

Ge, Y., Zhang, J.B., Zhang, L.M., Yang, M., He, J.Z., 2008. Long-term fertilization regimes affect bacterial community structure and diversity of an agricultural soil in northern China. Journal of Soils and Sediments 8, 43-50.

Griffiths, R.I., Thomson, B.C., James, P., Bell, T., Bailey, M., Whiteley, A.S., 2011. The bacterial biogeography of British soils. Environmental Microbiology 13, 1642-1654.

Hartmann, M., Frey, B., Mayer, J., Mäder, P., Widmer, F., 2015. Distinct soil microbial diversity under long-term organic and conventional farming. ISME Journal 9, 1177-1194.

Helgason, B.L., Walley, F.L., Germida, J.J., 2010. Long-term no-till management affects microbial biomass but not community composition in Canadian prairie agroecosytems. Soil Biology \& Biochemistry 42, 2192-2202.

Hemmat, A., Aghilinategh, N., Rezainejad, Y., Sadeghi, M., 2010. Long-term impacts of municipal solid waste compost, sewage sludge and farmyard manure application on organic carbon, bulk density and consistency limits of a calcareous soil in central iran. Soil \& Tillage Research 108, 43-50.

Horrigan, L., Lawrence, R.S., Walker, P., 2002. How sustainable agriculture can address the environmental and human health harms of industrial agriculture. Environmental Health Perspectives $110,445-456$
Ji, L., Wu, Z., You, Z., Yi, X., Ni, K., Guo, S., Ruan, J., 2018. Effects of organic substitution for synthetic $\mathrm{N}$ fertilizer on soil bacterial diversity and community composition: A 10 -year field trial in a tea plantation. Agriculture, Ecosystems \& Environment 268, 124-132.

Kennedy, A., 1999. Bacterial diversity in agroecosystems. Agriculture, Ecosystems \& Environment 74, 65-76.

Kumar, U., Nayak, A.K., Shahid, M., Gupta, V.V., Panneerselvam, P., Mohanty, S., Kaviraj, M., Kumar, A., Chatterjee, D., Lal, B., Gautam, P., Tripathi, R., Gautam, P., 2018. Continuous application of inorganic and organic fertilizers over 47 years in paddy soil alters the bacterial community structure and its influence on rice production. Agriculture, Ecosystems \& Environment 262, 65-75.

Larkin, R.P., Honeycutt, C.W., 2006. Effects of different 3-year cropping systems on soil microbial communities and rhizoctonia diseases of potato. Phytopathology 96, 68-79.

Lauber, C.L., Strickland, M.S., Bradford, M.A., Fierer, N., 2008. The influence of soil properties on the structure of bacterial and fungal communities across land-use types. Soil Biology \& Biochemistry 40, 2407-2415.

Lesaulnier, C., Papamichail, D., McCorkle, S., Ollivier, B., Skiena, S., Taghavi, S., Zak, D., van der Lelie, D., 2008. Elevated atmospheric $\mathrm{CO}_{2}$ affects soil microbial diversity associated with trembling aspen. Environmental Microbiology 10, 926-941.

Li, C.H., Yan, K., Tang, L.S., Jia, Z.J., Li, Y., 2014. Change in deep soil microbial communities due to long term fertilization. Soil Biology \& Biochemistry 75, 264-272.

Li, F., Chen, L., Zhang, J., Yin, J., Huang, S., 2017. Bacterial community structure after long-term organic and inorganic fertilization reveals important associations between soil nutrients and specific taxa involved in nutrient transformations. Frontiers in Microbiology 8, 187.

Liang, B., Wang, L.Y., Mbadinga, S.M., Liu, J.F., Yang, S.Z., Gu, J.D., $\mathrm{Mu}$, B.Z., 2015. Anaerolineaceae and Methanosaeta turned to be the dominant microorganisms in alkanes-dependent methanogenic culture after long-term of incubation. AMB Express 5, 117.

Liang, X.Q., Li, H., Wang, S.X., Ye, Y.S., Ji, Y.J., Tian, G.M., Kessel, C. V., Linquist, B.A., 2013. Nitrogen management to reduce yieldscaled global warming potential in rice. Field Crops Research 146, 66-74.

Ling, N., Zhu, C., Xue, C., Chen, H., Duan, Y., Peng, C., Guo, S., Shen, Q., 2016. Insight into how organic amendments can shape the soil microbiome in long-term field experiments as revealed by network analysis. Soil Biology \& Biochemistry 99, 137-149.

Litterick, A.M., Harrier, L., Wallace, P., Watson, C.A., Wood, M., 2004. The role of uncomposted materials, composts, manures, and compost extracts in reducing pest and disease incidence and severity in sustainable temperate agricultural and horticultural crop production-A review. Critical Reviews in Plant Sciences 23, 453479.

Liu, H., Li, J., Zhao, Y., Xie, K., Tang, X., Wang, S., Li, Z., Liao, Y., Xu, J., Di, H., Li, Y., 2018. Ammonia oxidizers and nitrite-oxidizing bacteria respond differently to long-term manure application in four paddy soils of south of China. Science of the Total Environment 633, 641-648.

Liu, H., Pan, H., Hu, H., Jia, Z., Zhang, Q., Liu, Y., Xu, J., Di, H., Li, Y., 2019. Autotrophic archaeal nitrification is preferentially stimulated 
by rice callus mineralization in a paddy soil. Plant and Soil 445, 5569.

Liu, J., Sui, Y., Yu, Z., Yu, S., Chu, H., Jian, J., Liu, X., Wang, G., 2014. High throughput sequencing analysis of biogeographical distribution of bacterial communities in the black soils of northeast China. Soil Biology \& Biochemistry 70, 113-122.

Ma, B., Wang, H., Dsouza, M., Lou, J., He, Y., Dai, Z., Brookes, P.C., Xu, J., Gilbert, J.A., 2016. Geographic patterns of co-occurrence network topological features for soil microbiota at continental scale in eastern China. ISME Journal 10, 1891-1901.

Mando, A., Ouattara, B., Sédogo, M., Stroosnijder, L., Ouattara, K., Brussaard, L., Vanlauwe, B., 2005. Long-term effect of tillage and manure application on soil organic fractions and crop performance under Sudano-Sahelian conditions. Soil \& Tillage Research 80, 95-101.

Marschner, P., Kandeler, E., Marschner, B., 2003. Structure and function of the soil microbial community in a long-term fertilizer experiment. Soil Biology \& Biochemistry 35, 453 461.

Mendes, R., Kruijt, M., de Bruijn, I., Dekkers, E., van der Voort, M., Schneider, J.H.M., Piceno, Y.M., DeSantis, T.Z., Andersen, G.L., Bakker, P.A.H.M., Raaijmakers, J.M., 2011. Deciphering the rhizosphere microbiome for disease-suppressive bacteria. Science 332, 1097-1100.

Navarrete, A.A., Soares, T., Rossetto, R., van Veen, J.A., Tsai, S.M., Kuramae, E.E., 2015. Verrucomicrobial community structure and abundance as indicators for changes in chemical factors linked to soil fertility. Antonie van Leeuwenhoek 108, 741-752.

Newton, R.J., McMahon, K.D., 2011. Seasonal differences in bacterial community composition following nutrient additions in a eutrophic lake. Environmental Microbiology 13, 887-899.

Noble, A.D., Zenneck, I., Randall, P.J., 1996. Leaf litter ash alkalinity and neutralisation of soil acidity. Plant and Soil 179, 293-302.

Olsen, S.R., 1954. Estimation of Available Phosphorus in Soils by Extraction with Sodium Bicarbonate. Miscellaneous Paper Institute for Agricultural Research Samaru.

Paul, E.A., 2014. Soil Microbiology, Ecology and Biochemistry. Elsevier Academic Press, Amsterdam.

Peacock, A., Mullen, M.D., Ringelberg, D.B., Tyler, D.D., Hedrick, D. B., Gale, P.M., White, D.C., 2001. Soil microbial community responses to dairy manure or ammonium nitrate applications. Soil Biology \& Biochemistry 33, 1011-1019.

Peters, R.D., Sturz, A.V., Carter, M.R., Sanderson, J.B., 2003. Developing disease-suppressive soils through crop rotation and tillage management practices. Soil \& Tillage Research 72, 181192.

Prosser, J.I., Head, I.M., Stein, L.Y., 2014. The Family Nitrosomonadaceae. In: Rosenberg, E., DeLong, E.F., Lory, S., Stackebrandt, E., Thompson, F., eds. The Prokaryotes. Springer, Berlin, Heidelberg.

Rawat, S.R., Männistö, M.K., Bromberg, Y., Häggblom, M.M., 2012. Comparative genomic and physiological analysis provides insights into the role of Acidobacteria in organic carbon utilization in Arctic tundra soils. FEMS Microbiology Ecology 82, 341-355.

Reeves, D.W., 1997. The role of soil organic matter in maintaining soil quality in continuous cropping systems. Soil \& Tillage Research 43, 131-167.
Reinhold-Hurek, B., Bünger, W., Burbano, C.S., Sabale, M., Hurek, T., 2015. Roots shaping their microbiome: global hotspots for microbial activity. Annual Review of Phytopathology 53, 403-424.

Rousk, J., Bååth, E., Brookes, P.C., Lauber, C.L., Lozupone, C., Caporaso, J.G., Knight, R., Fierer, N., 2010. Soil bacterial and fungal communities across a pH gradient in an arable soil. ISME Journal 4, 1340-1351.

Sachs, J.L., Simms, E.L., 2006. Pathways to mutualism breakdown. Trends in Ecology \& Evolution 21, 585-592.

Segata, N., Izard, J., Waldron, L., Gevers, D., Miropolsky, L., Garrett, W.S., Huttenhower, C., 2011. Metagenomic biomarker discovery and explanation. Genome Biology 12, R60.

Sharma, S.K., Ramesh, A., Sharma, M.P., Joshi, O.P., Govaerts, B., Steenwerth, K.L., Karlen, D.L., 2011. Microbial community structure and diversity as indicators for evaluating soil quality. In: Lichtfouse, E., ed. Biodiversity, Biofuels, Agroforestry and Conservation Agriculture. Springer Netherlands, pp. 317-358.

Shen, F., Wu, J., Fan, H., Liu, W., Guo, X., Duan, H., Hu, L., Lei, X., Wei, $X ., 2019$. Soil N/P and C/P ratio regulate the responses of soil microbial community composition and enzyme activities in a longterm nitrogen loaded Chinese fir forest. Plant and Soil 436, 91-107.

Smith, R.G., Gross, K.L., Robertson, G.P., 2008. Effects of crop diversity on agroecosystem function: crop yield response. Ecosystems (New York, N.Y.) 11, 355-366.

Soman, C., Li, D., Wander, M.M., Kent, A.D., 2017. Long-term fertilizer and crop-rotation treatments differentially affect soil bacterial community structure. Plant and Soil 413, 145-159.

Steiner, C., Teixeira, W.G., Lehmann, J., Nehls, T., de Macêdo, J.L.V., Blum, W.E.H., Zech, W., 2007. Long term effects of manure, charcoal and mineral fertilization on crop production and fertility on a highly weathered Central Amazonian upland soil. Plant Soil 291, 275-290.

Sterner, R.W., Elser, J.J., 2002. Ecological Stoichiometry, The Biology of Elements from Molecules to the Biosphere. Princeton University Press, Princeton, NY, USA.

Stubner, S., 2002. Enumeration of $16 \mathrm{~S}$ rDNA of Desulfotomaculum lineage 1 in rice field soil by real-time PCR with SybrGreen detection. Journal of Microbiological Methods 50, 155-164.

Sul, W.J., Cole, J.R., Jesus, E.C., Wang, Q., Farris, R.J., Fish, J.A., Tiedje, J.M., 2011. Bacterial community comparisons by taxonomy-supervised analysis independent of sequence alignment and clustering. Proceedings of the National Academy of Sciences of the United States of America 108, 14637-14642.

Sun, J., Zhang, Q., Zhou, J., Wei, Q., 2014. Pyrosequencing technology reveals the impact of different manure doses on the bacterial community in apple rhizosphere soil. Applied Soil Ecology 78, 28-36.

Sun, R., Zhang, X.X., Guo, X., Wang, D., Chu, H., 2015. Bacterial diversity in soils subjected to long-term chemical fertilization can be more stably maintained with the addition of livestock manure than wheat straw. Soil Biology \& Biochemistry 88, 9-18.

Tiemann, L.K., Grandy, A.S., Atkinson, E.E., Marin-Spiotta, E., McDaniel, M.D., 2015. Crop rotational diversity enhances belowground communities and functions in an agroecosystem. Ecology Letters 18, 761-771.

Tveit, A.T., Urich, T., Svenning, M.M., 2014. Metatranscriptomic 
analysis of arctic peat soil microbiota. Applied and Environmental Microbiology 80, 5761-5772.

Umezawa, K., Watanabe, T., Miura, A., Kojima, H., Fukui, M., 2016. The complete genome sequences of sulfur-oxidizing Gammaproteobacteria Sulfurifustis variabilis skN76(T) and Sulfuricaulis limicola HA5(T). Standards in Genomic Sciences 11, 71.

Venter, Z.S., Jacobs, K., Hawkins, H.J., 2016. The impact of crop rotation on soil microbial diversity, a meta-analysis. Pedobiologia 59, 215-223.

Wang, J., Yang, S., Ma, T., Raza, W., Jing, L., Howland, J.G., Huang, Q., Shen, Q., 2017. Impacts of inorganic and organic fertilization treatments on bacterial and fungal communities in a paddy soil. Applied Soil Ecology 112, 42-50.

Wang, Y., Guo, J., Vogt, R.D., Mulder, J., Wang, J., Zhang, X., 2018. Soil $\mathrm{pH}$ as the chief modifier for regional nitrous oxide emissions: New evidence and implications for global estimates and mitigation. Global Change Biology 24, e617-e626.

Warembourg, F.R., Roumet, C., Lafont, F., 2003. Differences in rhizosphere carbon-partitioning among plant species of different families. Plant and Soil 256, 347-357.

Watts, D.B., Torbert, H.A., Feng, Y., Prior, S.A., 2010. Soil microbial community dynamics as influenced by composted dairy manure, soil properties, and landscape position. Soil Science 175, 474 486.

Wu, M.N., Qin, H.L., Chen, Z., Wu, J.S., Wei, W.X., 2011. Effect of long-term fertilization on bacterial composition in rice paddy soil. Biology and Fertility of Soils 47, 397-405.

Xia, L., Lam, S.K., Yan, X., Chen, D., 2017. How does recycling of livestock manure in agroecosystems affect crop productivity, reactive nitrogen losses and soil carbon balance? Environmental Science \& Technology 51, 7450-7457.

Xia, W., Zhang, C., Zeng, X., Feng, Y., Weng, J., Lin, X., Zhu, J., Xiong, Z., Xu, J., Cai, Z., Jia, Z., 2011. Autotrophic growth of nitrifying community in an agricultural soil. ISME Journal 5, 1226 1236.

Xuan, D.T., Guong, V.T., Rosling, A., Alström, S., Chai, B., Högberg, N., 2012. Different crop rotation systems as drivers of change in soil bacterial community structure and yield of rice, Oryza sativa. Biology and Fertility of Soils 48, 217-225.

Yang, Y., Li, X., Liu, J., Zhou, Z., Zhang, T., Wang, X., 2017. Bacterial diversity as affected by application of manure in red soils of subtropical China. Biology and Fertility of Soils 53, 639-649.
Yang, Y., Wang, P., Zeng, Z., 2019. Dynamics of bacterial communities in a 30-year fertilized paddy field under different organicinorganic fertilization strategies. Agronomy (Basel) 9, 14.

Yin, C., Jones, K.L., Peterson, D.E., Garrett, K.A., Hulbert, S.H., Paulitz, T.C., 2010. Members of soil bacterial communities sensitive to tillage and crop rotation. Soil Biology \& Biochemistry 42, 2111-2118.

Yu, H.Y., Ding, W.X., Luo, J.F., Donnison, A., Zhang, J.B., 2012. Longterm effect of compost and inorganic fertilizer on activities of carbon-cycle enzymes in aggregates of an intensively cultivated sandy loam. Soil Use and Management 28, 347-360.

Zhang, Q.C., Shamsi, I.H., Xu, D.T., Wang, G.H., Lin, X.Y., Jilani, G., Hussain, N., Chaudhry, A.N., 2012. Chemical fertilizer and organic manure inputs in soil exhibit a vice versa pattern of microbial community structure. Applied Soil Ecology 57, 1-8.

Zhang, X., Zhang, R., Gao, J., Wang, X., Fan, F., Ma, X., Yin, H., Zhang, C., Kai, F., Ye, D., 2017. Thirty-one years of rice-rice-green manure rotations shape the rhizosphere microbial community and enrich beneficial bacteria. Soil Biology \& Biochemistry 104, 208217.

Zhao, J., Zhang, R., Xue, C., Xun, W., Sun, L., Xu, Y., Shen, Q., 2014. Pyrosequencing reveals contrasting soil bacterial diversity and community structure of two main winter wheat cropping systems in China. Microbial Ecology 67, 443-453.

Zhao, L., Dong, Y.H., Wang, H., 2010. Residues of veterinary antibiotics in manures from feedlot livestock in eight provinces of China. Science of the Total Environment 408, 1069-1075.

Zhong, W., Gu, T., Wang, W., Zhang, B., Lin, X., Huang, Q., Shen, W., 2010. The effects of mineral fertilizer and organic manure on soil microbial community and diversity. Plant and Soil 326, 511-522.

Zhou, J., Deng, Y., Luo, F., He, Z., Yang, Y., 2011. Phylogenetic molecular ecological network of soil microbial communities in response to elevated $\mathrm{CO}_{2}$. mBio 2, e00122-e11.

Zhou, J., Guan, D., Zhou, B., Zhao, B., Ma, M., Qin, J., Jiang, X., Chen, S., Cao, F., Shen, D., Li, J., 2015. Influence of 34-years of fertilization on bacterial communities in an intensively cultivated black soil in northeast China. Soil Biology \& Biochemistry 90, 4251.

Zhou, J., Jiang, X., Wei, D., Zhao, B., Ma, M., Chen, S., Cao, F., Shen, D., Guan, D., Li, J., 2017. Consistent effects of nitrogen fertilization on soil bacterial communities in black soils for two crop seasons in China. Scientific Reports 7, 3267. 